\title{
Fructose to Sorbents: Synthesis of Metal- Organic Frameworks Directly from Biomass for Humid Shale Gas Separation
}

Yi-Ming Gu, ${ }^{\dagger, \star}$ Hai-Feng Qi, ${ }^{\dagger, \dagger}$ Salman Qadir,,$+\star$ Xiao-Wei Liu,,$* *$ Tian-Jun Sun, ${ }^{\dagger}$ Sheng-Sheng

Zhao, ${ }^{\dagger}$ Zhiping Lai, ${ }^{\|}$and Shu-Dong Wang ${ }^{\dagger, *}$

$\dagger$ Dalian National Laboratory for Clean Energy, Dalian Institute of Chemical Physics, Chinese Academy of Sciences, Dalian 116023, China.

$\$$ University of Chinese Academy of Sciences, Beijing 100049, China.

\| Advanced Membranes and Porous Materials Center, Division of Physical Sciences and Engineering, King Abdullah University of Science and Technology (KAUST), Thuwal, 23955-6900 Saudi Arabia.

Numbers of Page 42

Numbers of Figure 43

Numbers of Table 11 


\section{Contents}

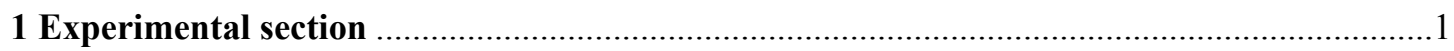

1.1 Synthesis of intermediates and MOFs from biomass .....................................................

1.2 Solution ${ }^{1} \mathrm{H}$ NMR of digested samples …….............................................................

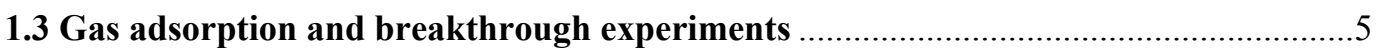

2 Crystal structure measurement and analyses …….......................................................

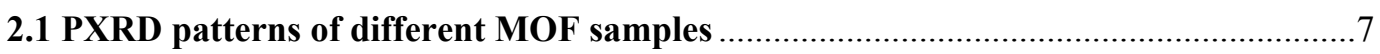

2.2 Fourier transform infrared (FTIR) spectroscopy ……............................................

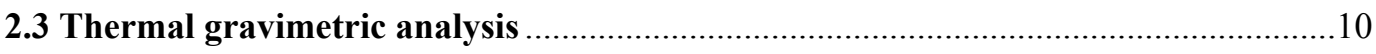

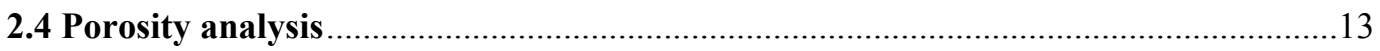

2.5 Comparison of MIL-160(Al) produced using different ligands ................................18

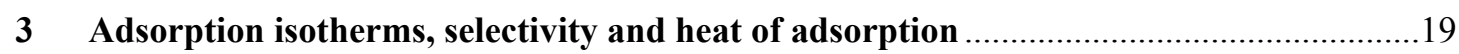

3.1 Gas adsorption isotherms on the renewable MOFs....................................................19

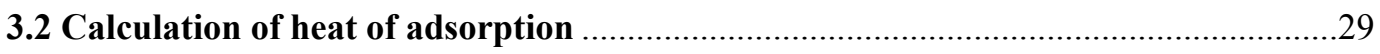

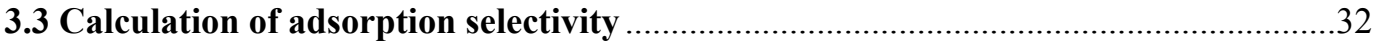

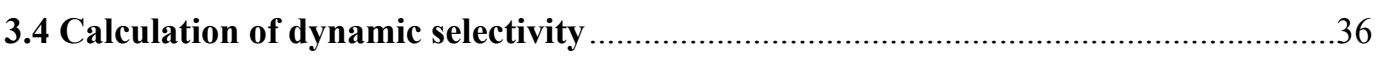

$4 \quad$ Water microcalorimetric and adsorption measurement ....................................................37

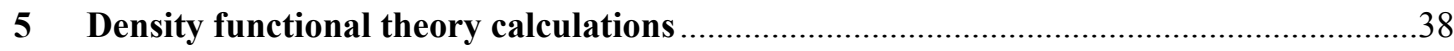

6 Summary of $\mathrm{C}_{2} \mathrm{H}_{6}$ adsorption and separation performance of MOFs............................39

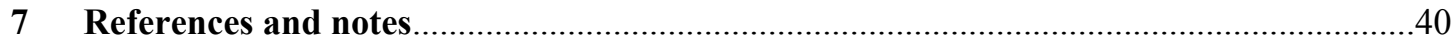




\section{Experimental section}

\subsection{Synthesis of intermediates and MOFs from biomass}

The conversion of reactant $A\left(\mathrm{X}_{A}\right)$ and the yield of product $B\left(\mathrm{Y}_{B}\right)$ were calculated using the following equations:

$$
\begin{aligned}
& \mathrm{X}_{A}(\%)=\left(\mathrm{mol}_{\text {A consumed }}\right) /\left(\mathrm{mol}_{A \text { fed }}\right) * 100 \\
& \mathrm{Y}_{B}(\%)=\left(\mathrm{mol}_{B \text { produced }}\right) /\left(\mathrm{mol}_{B \text { fed }}\right) * 100
\end{aligned}
$$

The liquid products were collected and analyzed by HPLC on an Agilent 1200 system equipped with a Phenomenex Rezex RQA-Organic Acid $\mathrm{H}^{+}(8 \%)$ column and a differential refractive index detector (RID).

Synthesis 1: $\beta$-fructose dehydration and purification

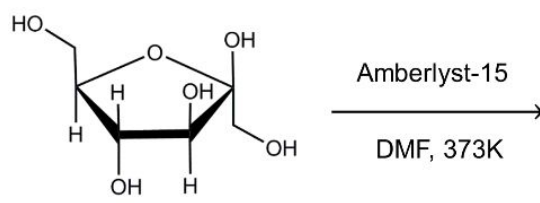

$\beta$-fructose<smiles>O=Cc1ccc(CO)o1</smiles>

HMF

The synthesis of HMF from $\beta$-fructose followed a reported work with minor changes. ${ }^{1-2} 0.3 \mathrm{~g}$ (1.67 mmol) of $\beta$-fructose ( $>99 \%$; Macklin) was first dissolved in $\mathrm{N}, \mathrm{N}$-dimethyl-formamide (DMF, $10 \mathrm{~mL}$; Kermel) for $5 \mathrm{~min}$. After adding $0.3 \mathrm{~g}$ of catalyst Amberlyst-15, the color of the mixture solution turned jacinth. The mixture was then placed in an oil bath at $373 \mathrm{~K}$ and stirred for another $3 \mathrm{~h}\left(\mathrm{X}_{\beta}=100 ; \mathrm{Y}_{H M F}>\right.$ 91). After it was cooled down to room temperature, Amberlyst-15 was filtered out, and $0.1 \mathrm{~g}$ of commercial active carbon (30 60 mesh; Shimadzu) was added to the system to adsorb humins generated during fructose dehydration. The obtained enriching solution was then stirred for $40 \mathrm{~min}$, and afterwards centrifuged to remove the activated carbon. The color of the final solution turned orange, and HMF was determined via HPLC analysis of the final solution.

Synthesis 2: HMF oxidation<smiles>O=Cc1ccc(CO)o1</smiles>

HMF

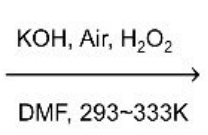

DMF, 293 333K<smiles>O=C(O)c1ccc(C(=O)O)o1</smiles>

FDCA

The oxidation of HMF to FDCA followed a reported work with changes. ${ }^{3} 10 \mathrm{ml}$ of the HMF enriching DMF solution from Synthesis 1 was first diluted with $14.8 \mathrm{ml}$ of 
fresh DMF, and then $10 \mathrm{ml}$ of the obtained solution was taken and introduced to a 20 $\mathrm{ml}$ Teflon container under stirring. $0.112 \mathrm{~g}$ of KOH flakes ( $2 \mathrm{mmol},>99 \%$; Sinopharm) were then added to the container, and the mixture solution was introduced with a 30 $\mathrm{ml} / \mathrm{min}$ air flow at $293 \mathrm{~K}$. After $6 \mathrm{~h}, 1 \mathrm{ml}$ of hydrogen peroxide ( $>30 \mathrm{wt} . \%$ aq.; Sinopharm) was carefully injected into the solution, and the reaction system with air flow at $333 \mathrm{~K}$ was placed for another $14 \mathrm{~h}$. During the whole process a number of gas bubbles were generated around the alkali catalyst, which turned the catalyst into foam and suspended in the agitated solution. As the reaction went on, flocculent FDCK (the potassium salt version of FDCA) was also observed in the solution, and the color of the solution gradually changed from deep yellow in the beginning to a bit colorless upon completion of the oxidation, while the product, i.e., FDCK, would finally deposit in the bottom. After the floating catalyst was removed, $\mathrm{HNO}_{3}(1 \mathrm{M}, 2 \sim 3$ drops, ca. $0.1 \mathrm{ml})$ was then added into the solution, this transformed the FDCK precipitates to soluble FDCA in DMF (Figure S1) with a solution $\mathrm{pH}$ value of 7.4 7.7. The concentration of FDCA was determined via HPLC analysis of the final solution $\left(\mathrm{X}_{H M F}=100 ; \mathrm{Y}_{F D C A}>96\right)$.

Synthesis 3: Synthesis of MIL-160(Al)

$0.1875 \mathrm{~g}$ of $\mathrm{Al}\left(\mathrm{NO}_{3}\right)_{3} \cdot 9 \mathrm{H}_{2} \mathrm{O}(0.5 \mathrm{mmol},>99 \%$; Sinopharm $)$ was first dissolved in $14 \mathrm{ml}$ of nitric-acidified FDCA enriching solution from Synthesis 2 in a $20 \mathrm{ml}$ Teflon container. The container was then sealed and put in a programmed heating oven at 393 $\mathrm{K}$ for $48 \mathrm{~h}$. Once it was naturally cooled down to room temperature, white powders of MIL-160(Al) were collected by centrifuge, and then washed with DMF and ethanol several times. After further thoroughly exchanged with anhydrous ethanol, the final samples were dried in a vacuum oven at $333 \mathrm{~K}$ for $24 \mathrm{~h}\left(\mathrm{Y}_{M O F}=97.4\right.$ based on metal).

For comparison, MIL-160(Al) was also produced using the commercially available FDCA ( $>99 \%$ AR, Meryer) following the similar procedure as above.

Synthesis 4-6: Synthesis of metallic clusters for PCN-233 series MOFs

The synthesis of metallic clusters for PCN233 MOF series was following the reported literature as follows: ${ }^{4-6} 25.43 \mathrm{~g}$ of $\mathrm{CH}_{3} \mathrm{COONa}$ (310 mmol, $>99.9 \%$; Macklin) and $8.08 \mathrm{~g}$ of $\mathrm{Fe}\left(\mathrm{NO}_{3}\right)_{3} \cdot 9 \mathrm{H}_{2} \mathrm{O}$ (20 mmol, $>99.9 \%$; Macklin) were firstly dissolved in $50 \mathrm{ml}$ of deionized water, respectively. Then divalent metallic salts, represented as $\mathrm{M}$, were added into the $\mathrm{Fe}\left(\mathrm{NO}_{3}\right)_{3}$ solution and dissolved under stirring for $10 \mathrm{~min}$. Afterwards, the $\mathrm{CH}_{3} \mathrm{COONa}$ solution was slowly introduced into $\mathrm{Fe}\left(\mathrm{NO}_{3}\right)_{3}$ solution under stirring, and the resulting mixed turbid solution was stirred for another $24 \mathrm{~h}$ at room temperature. After the reaction was complete, brown precipitates were collected by filtration, and then washed with water and ethanol several times. The final samples were dried in a vacuum oven at $333 \mathrm{~K}$ for $12 \mathrm{~h}$.

Synthesis of $\mathrm{Fe}_{2} \mathrm{Ni}\left(\mu_{3}-\mathrm{O}\right)\left(\mathrm{CH}_{3} \mathrm{COO}\right)_{6}: \mathrm{M}$ is $29.10 \mathrm{~g}$ of $\mathrm{Ni}\left(\mathrm{NO}_{3}\right)_{2} \cdot 6 \mathrm{H}_{2} \mathrm{O}(100 \mathrm{mmol}$, $>99.9 \%$; Macklin);

Synthesis of $\mathrm{Fe}_{2} \mathrm{Co}\left(\mu_{3}-\mathrm{O}\right)\left(\mathrm{CH}_{3} \mathrm{COO}\right)_{6}: \mathrm{M}$ is $29.10 \mathrm{~g}$ of $\mathrm{Co}\left(\mathrm{NO}_{3}\right)_{2} \cdot 6 \mathrm{H}_{2} \mathrm{O}(100 \mathrm{mmol}$, $>99.9 \%$; Macklin); 
Synthesis of $\mathrm{Fe}_{2} \mathrm{Mn}\left(\mu_{3}-\mathrm{O}\right)\left(\mathrm{CH}_{3} \mathrm{COO}\right)_{6}: \mathrm{M}$ is $35.90 \mathrm{~g}$ of $\mathrm{Mn}\left(\mathrm{NO}_{3}\right)_{2}$ solution (100 mmol, 50 wt.\% aq.; Macklin)

\section{Synthesis 7-9: Synthesis of PCN-233 series MOFs}

A certain amount of metallic cluster powders from Synthesis 4-6, $35 \mathrm{ml}$ of nitricacidified FDCA enriching solution from Synthesis 2, $10 \mathrm{ml}$ of DMF and $40 \mu \mathrm{l}$ of HF were homogeneously mixed in a $100 \mathrm{ml}$ Teflon container under stirring. The container was then sealed and heated in an oven at $398 \mathrm{~K}$ for $24 \mathrm{~h}$. Once it was naturally cooled down to room temperature, dark brown powders were collected by centrifuge, and then washed with DMF and ethanol several times. After further thoroughly exchanged with anhydrous ethanol, the final samples were dried in a vacuum oven at $333 \mathrm{~K}$ for $24 \mathrm{~h}$.

Synthesis of FeNi-PCN233: $\mathrm{M}$ is $0.27 \mathrm{~g}(0.5 \mathrm{mmol})$ of $\mathrm{Fe}_{2} \mathrm{Ni}\left(\mu_{3}-\mathrm{O}\right)\left(\mathrm{CH}_{3} \mathrm{COO}\right)_{6}$ $\left(\mathrm{Y}_{M O F}=95.0\right.$ based on metal);

Synthesis of FeCo-PCN233: $\mathrm{M}$ is $0.27 \mathrm{~g}(0.5 \mathrm{mmol})$ of $\mathrm{Fe}_{2} \mathrm{Co}\left(\mu_{3}-\mathrm{O}\right)\left(\mathrm{CH}_{3} \mathrm{COO}\right)_{6}$ $\left(\mathrm{Y}_{M O F}=94.8\right.$ based on metal);

Synthesis of FeNi-PCN233: $\mathrm{M}$ is $0.26 \mathrm{~g}(0.5 \mathrm{mmol})$ of $\mathrm{Fe}_{2} \mathrm{Mn}\left(\mu_{3}-\mathrm{O}\right)\left(\mathrm{CH}_{3} \mathrm{COO}\right)_{6}$ $\left(\mathrm{Y}_{M O F}=96.5\right.$ based on metal).
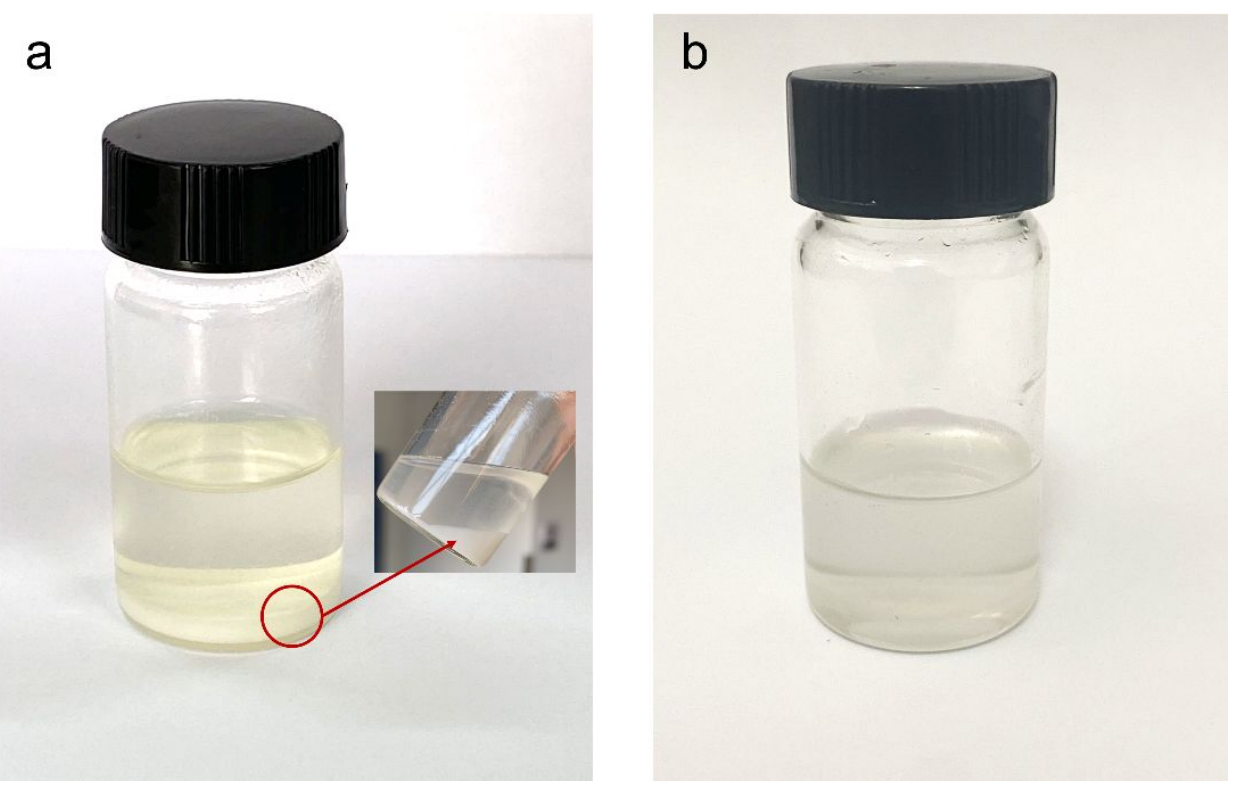

Figure S1 The product solution from HMF oxidation in Synthesis 2. (a) Whiteyellowish potassium FDCA (FDCK) deposited in the solution after reaction (floating catalysts have been removed); (b) Nitric-acidified FDCA solution from (a). 


\subsection{Solution ${ }^{1} \mathrm{H}$ NMR of digested samples}

After thoroughly washed with DMF, about $5 \mathrm{mg}$ of sediments obtained from synthesis 2 were dried in a dynamic vacuum oven at $333 \mathrm{~K}$ for $24 \mathrm{~h}$. Then, the sample was added into $0.5 \mathrm{ml}$ of $\mathrm{D}_{2} \mathrm{O}(>99.9 \%$, Innochem). The suspension was sonicated for $5 \mathrm{~min}$ and the solution turned to be clarified at $298 \mathrm{~K}$. In this solvent, some $\mathrm{H}$ atoms were exchanged by $\mathrm{D}$ atoms from the solvent, and details of $\mathrm{H}$ atoms from $\mathrm{H}_{2} \mathrm{O}$ and DMF were detected as follows. ${ }^{1} \mathrm{H}$ NMR $(700 \mathrm{MHz}$, Deuterium Oxide) $\delta 8.29(\mathrm{~s}, 1 \mathrm{H})$, $6.84(\mathrm{~s}, 14 \mathrm{H}), 4.43$ (s, 2H), $4.20-4.04(\mathrm{~m}, 2 \mathrm{H}), 3.01-2.65(\mathrm{~m}, 1 \mathrm{H}), 2.50$ (dd, J = 15.4, $3.0 \mathrm{~Hz}, 3 \mathrm{H}), 2.30-2.07(\mathrm{~m}, 3 \mathrm{H})$.

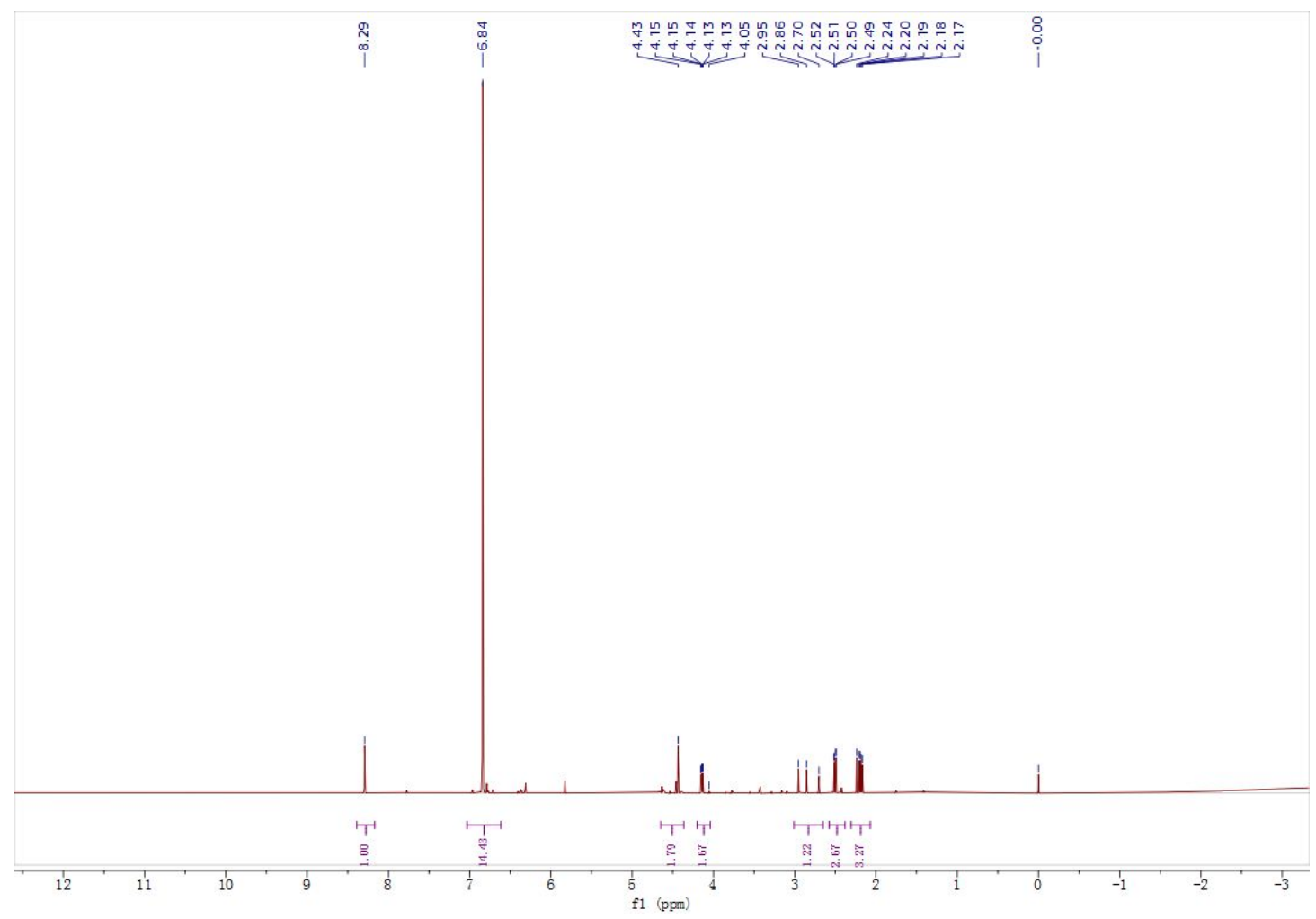

Figure S2 ${ }^{1} \mathrm{H}(700 \mathrm{MHz})$ spectra of obtained FDCK from Synthesis 2 digested sample in $50 \mathrm{mM} \mathrm{D}_{2} \mathrm{O}$ solution. 


\subsection{Gas adsorption and breakthrough experiments}

Gas sorption isotherms were measured using a Quantachrome Autosorb-iQ2 at 288, 298 and $308 \mathrm{~K}$ (water bath is under precise temperature control and recirculated by PolyScience AD07R-20-AA2Y) and $87 \mathrm{~K}$ (liquid argon bath). All gases were commercial with an ultra-high quality of $99.999 \%$ (for $\mathrm{CH}_{4}, \mathrm{C}_{2} \mathrm{H}_{6}, \mathrm{CO}_{2}, \mathrm{~N}_{2}$ and Ar). For adsorption, MOF samples were firstly evacuated under a dynamic vacuum in Autosorb-iQ2 at $353 \mathrm{~K}$ for $2 \mathrm{~h}$, and then activated to $433 \mathrm{~K}$ at the rate of $3 \mathrm{~K} / \mathrm{min}$ for $12 \mathrm{~h}$ (see TG data in section 2.3).

Water sorption isotherms were measured on an indoor intelligent gravimetric analysis instrument (model IGA-100, Hiden Analytical Ltd., Warrington, UK.) at room temperature. The temperature uncertainty and stability are 0.1 and $0.05 \mathrm{~K}$, respectively, which is regulated with a water bath or a heating furnace outside the reactor. The uptake of water vapor $(\mathrm{wt} \%)$ was calculated as [(excess molar quantity of water adsorbed $) \times$ (molar mass of water)/(amount of adsorbent) $\times 100]$, consistent with established procedures. Prior to vapor adsorption tests, samples were molded and sieved as 60 80 mesh, and dried at $433 \mathrm{~K}$ under a dynamic vacuum for $12 \mathrm{~h}$.

As shown in Figure S3, breakthrough experiments were all carried out using a homemade programmable control system armed with a thermostat and a humidistat to monitor the system temperature and humidity. The adsorption fixed bed was a $120 \mathrm{~mm}$ length and $4 \mathrm{~mm}$ inner-diameter tube, packed with ca. $0.42 \mathrm{~g}$ of MIL-160(Al) (particle size: $0.18 \sim 0.25 \mathrm{~mm}$ ). Samples were completely activated under a $\mathrm{He}$ flow at $433 \mathrm{~K}$ overnight, and then cooled down to room temperature using a temperature programmed water bath. Breakthrough experiments were performed with a stream of $5 \mathrm{ml} / \mathrm{min}$ $\mathrm{C}_{2} \mathrm{H}_{6} / \mathrm{CH}_{4}(5 / 95, \mathrm{v} / \mathrm{v})$ mixture or $5 \mathrm{ml} / \mathrm{min}_{2} \mathrm{C}_{6} / \mathrm{CH}_{4} / \mathrm{CO}_{2} / \mathrm{N}_{2}(5 / 93 / 0.5 / 1.5, \mathrm{v} / \mathrm{v} / \mathrm{v} / \mathrm{v})$ mixture simulating the shale gas, under both dry and moist condition at 1 bar, respectively. A vapor generator was employed to generate the moist with a relative humidity (RH) of $90 \pm 2 \%$ at $298 \mathrm{~K}$. The composition of gas from outlet was detected by an online mass spectrometry. All breakthrough experiments in this work were operated under constant conditions. 


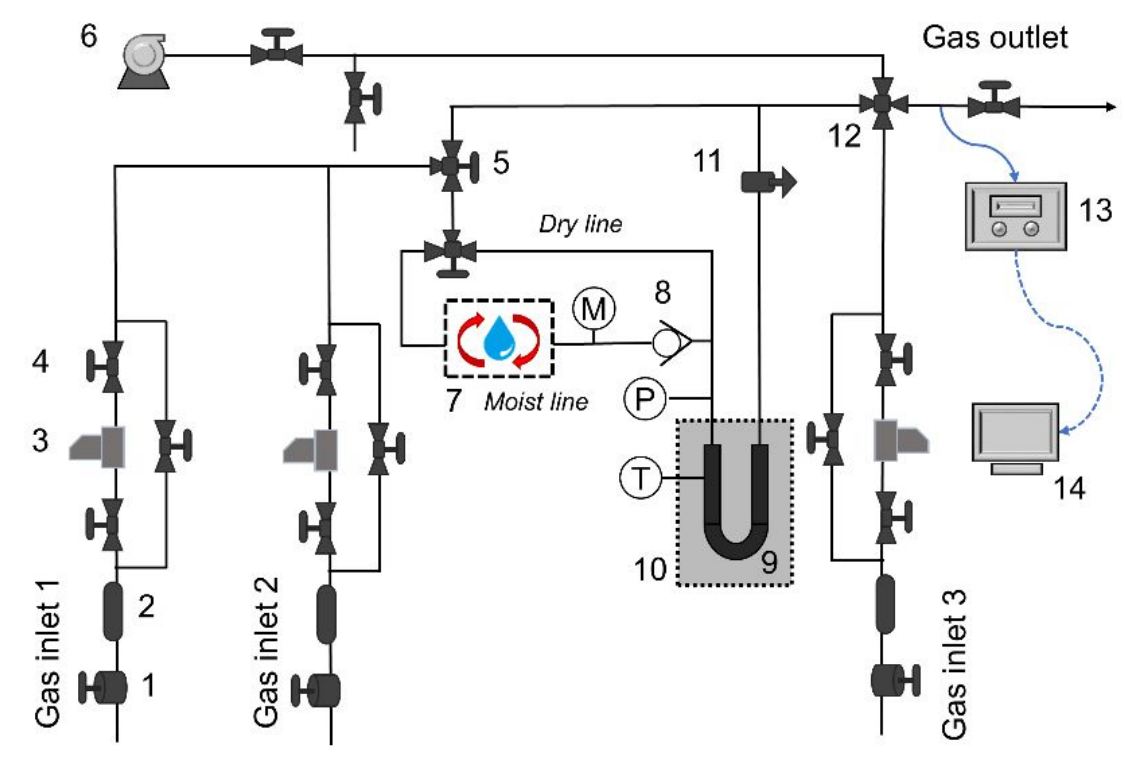

Figure S3 Schematic set-up with steam module for breakthrough experiments.

1 pressure reducing regulator; 2 gas purifier; 3 mass flow controller; 4 two-way valve; 5 three-way valve; 6 vacuum pump; 7 vapor generator; 8 one-way valve; 9 adsorbent bed; 10 thermostatic chamber; 11 back pressure; 12 four-way connection; 13 mass spectrometer; 14 computer.

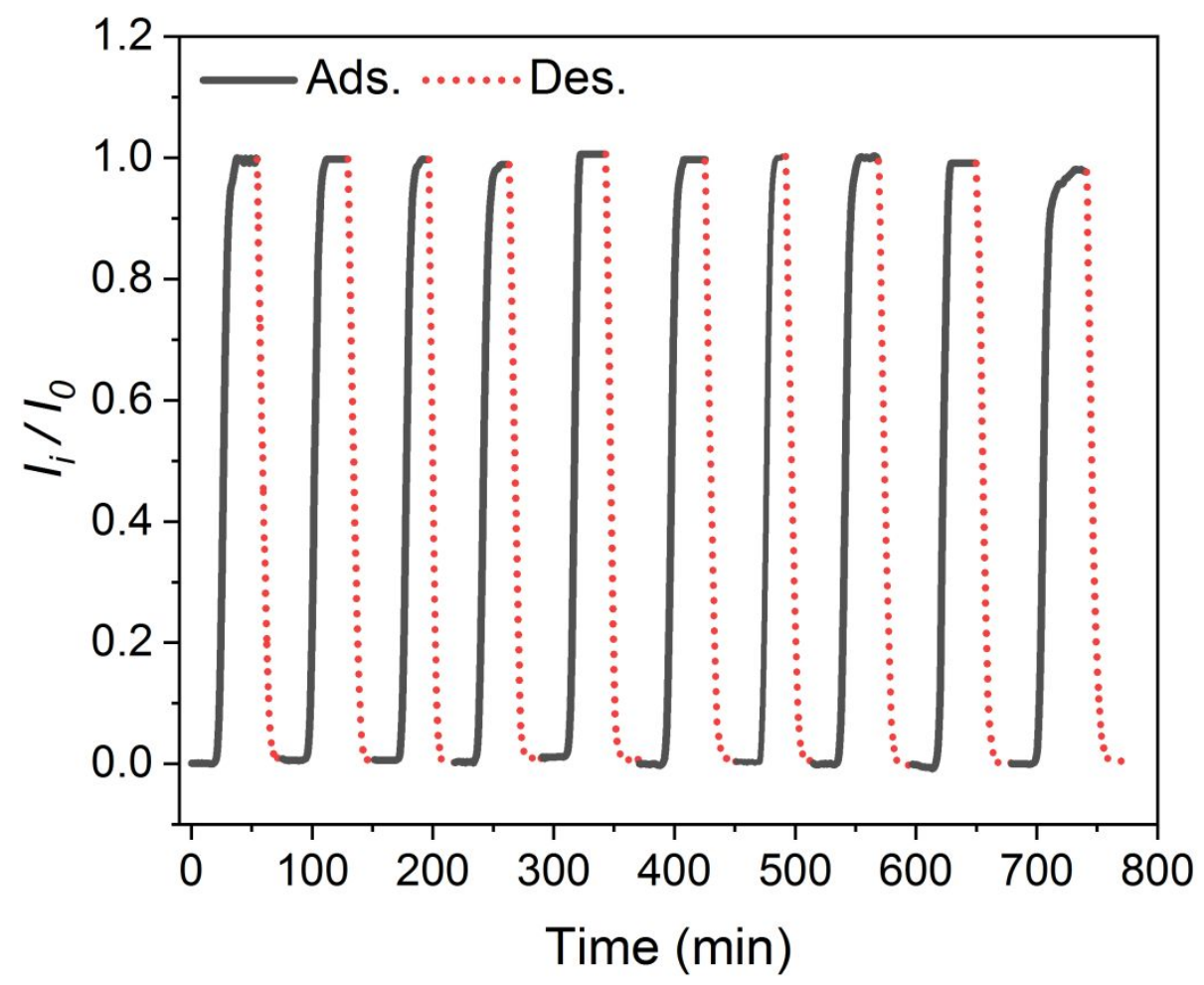

Figure S4 The recycle and regeneration tests for $\mathrm{C}_{2} \mathrm{H}_{6}$ capture on MIL-160 (Al) at $298 \mathrm{~K}, 1$ bar. 


\section{Crystal structure measurement and analyses}

\subsection{PXRD patterns of different MOF samples}

The Powder X-ray Diffraction (PXRD) patterns of renewable MOFs were measured on a PANalytical X'Pert Powder X-ray powder diffractometer operated at a voltage of $60 \mathrm{kV}$ and current of $55 \mathrm{~mA}$ with $\mathrm{CuK} \alpha$ radiation $(\lambda=1.5418 \AA)$.

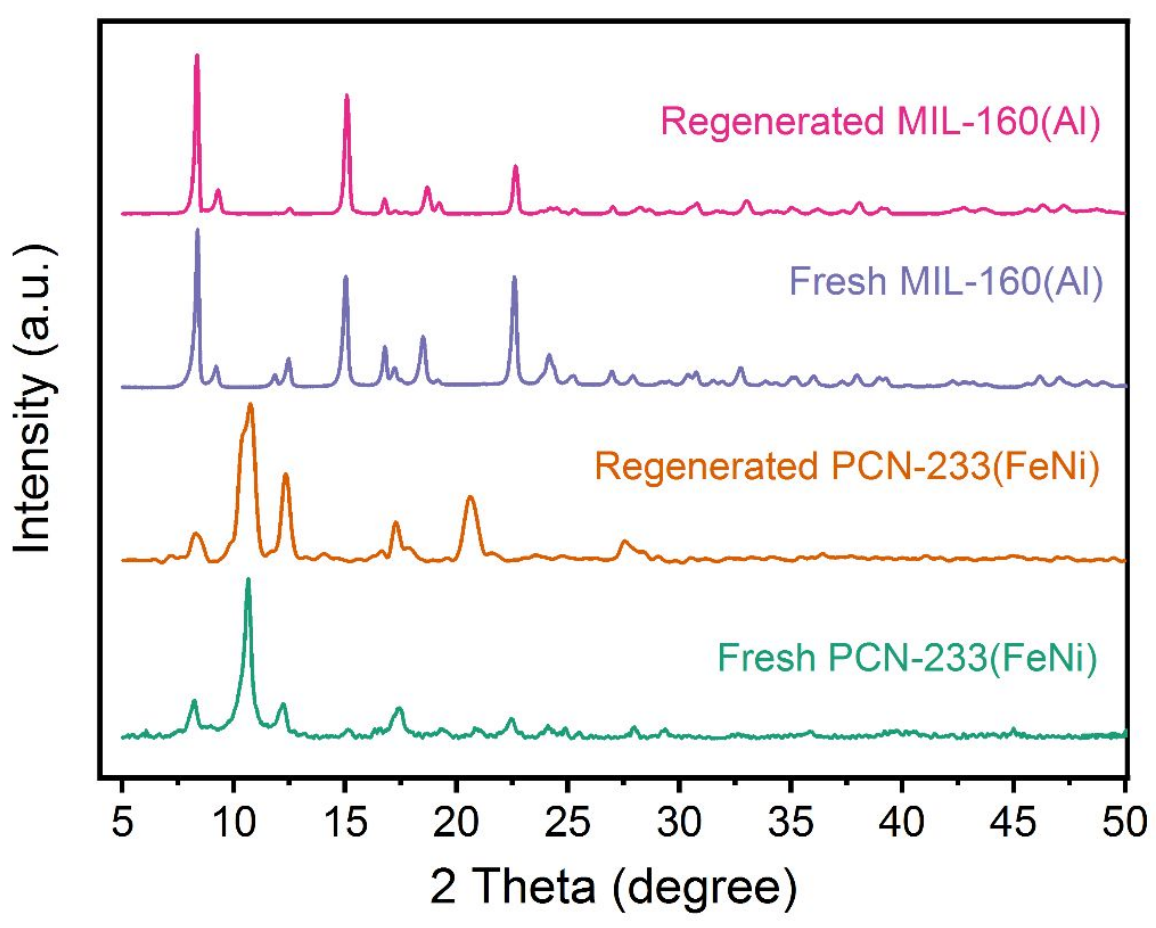

Figure S5 PXRD patterns of renewable MOFs for fresh and regenerated samples. For the regenerated MOFs, they first conducted a water sorption experiment to 1 bar at 298 $\mathrm{K}$, and afterwards, they were fully regenerated at $433 \mathrm{~K}$ under a dynamic vacuum. 


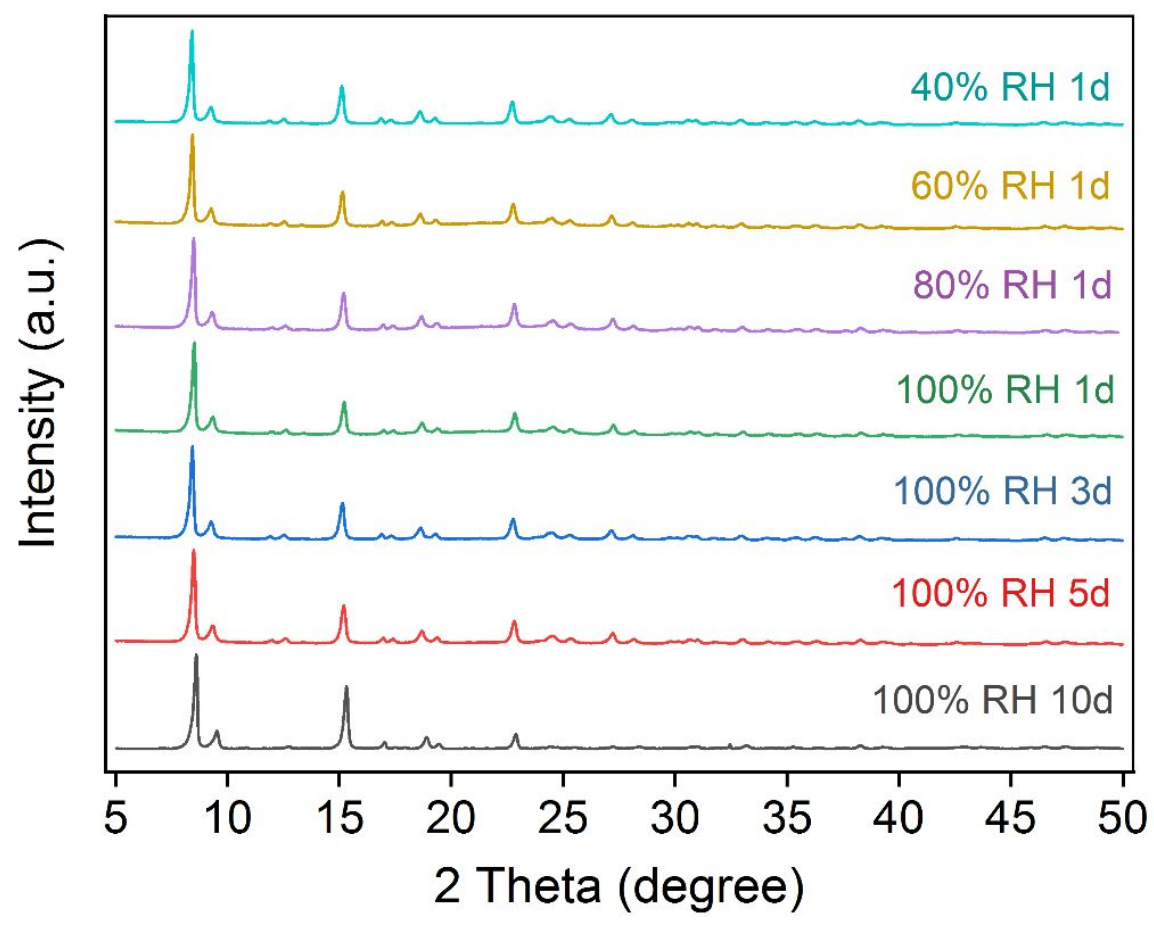

Figure S6 The PXRD patterns of MIL-160(Al) under different humid conditions at $298 \mathrm{~K}$ over time. 


\subsection{Fourier transform infrared (FTIR) spectroscopy}

Fourier transform infrared (FT-IR) spectra were carried out in the solid-state using a Nicolet 6700 FT-IR instrument equipped with a $\mathrm{KBr}$ beam splitter and an MTC nitrogen-cooled detector. Before experiments, MOFs samples and $\mathrm{KBr}$ powder were heating under infrared lamp for dehydration and drying for $6 \mathrm{~h}$. The spectra data were collected at the frequency region of $4000-600 \mathrm{~cm}^{-1}$ with a resolution of $4 \mathrm{~cm}^{-1}$. The FTIR results here verified the successful synthesis of the MOFs studied. The absence of peaks at $1700 \mathrm{~cm}^{-1}$ corresponding to the carboxylic acid groups suggested no residuals of free linker molecules existed in the samples. ${ }^{7}$ The spectra peaks at 820 and $970 \mathrm{~cm}^{-}$ ${ }^{1}$ could be assigned to the $\mathrm{C}-\mathrm{H}$ out-of-plane deformation vibrations of the furan ring, while peaks at $1010 \sim 1280 \mathrm{~cm}^{-1}$ correspond to the asymmetrical and symmetrical stretching vibrations of ester $\mathrm{C}-\mathrm{O}-\mathrm{C}$ groups and the $=\mathrm{C}-\mathrm{O}-\mathrm{C}=$ vibrations of the furan rings. ${ }^{8-9}$ The big signals observed at around 1415 and $1580 \mathrm{~cm}^{-1}$ may be ascribed to the wagging vibrations of the $-\mathrm{CH}$ - groups and the stretching vibrations of the $\mathrm{C}=\mathrm{C}$ bond in the furan ring, respectively. ${ }^{7-8}$ Besides, $=\mathrm{C}-\mathrm{H}$ stretching vibrations of the furan ring could be visible at $2700 \sim 3150 \mathrm{~cm}^{-1}$, and bands at 3000 3700 $\mathrm{cm}^{-1}$ could account for the stretching vibrations of $\mu-\mathrm{O}-\mathrm{H} .{ }^{9}$

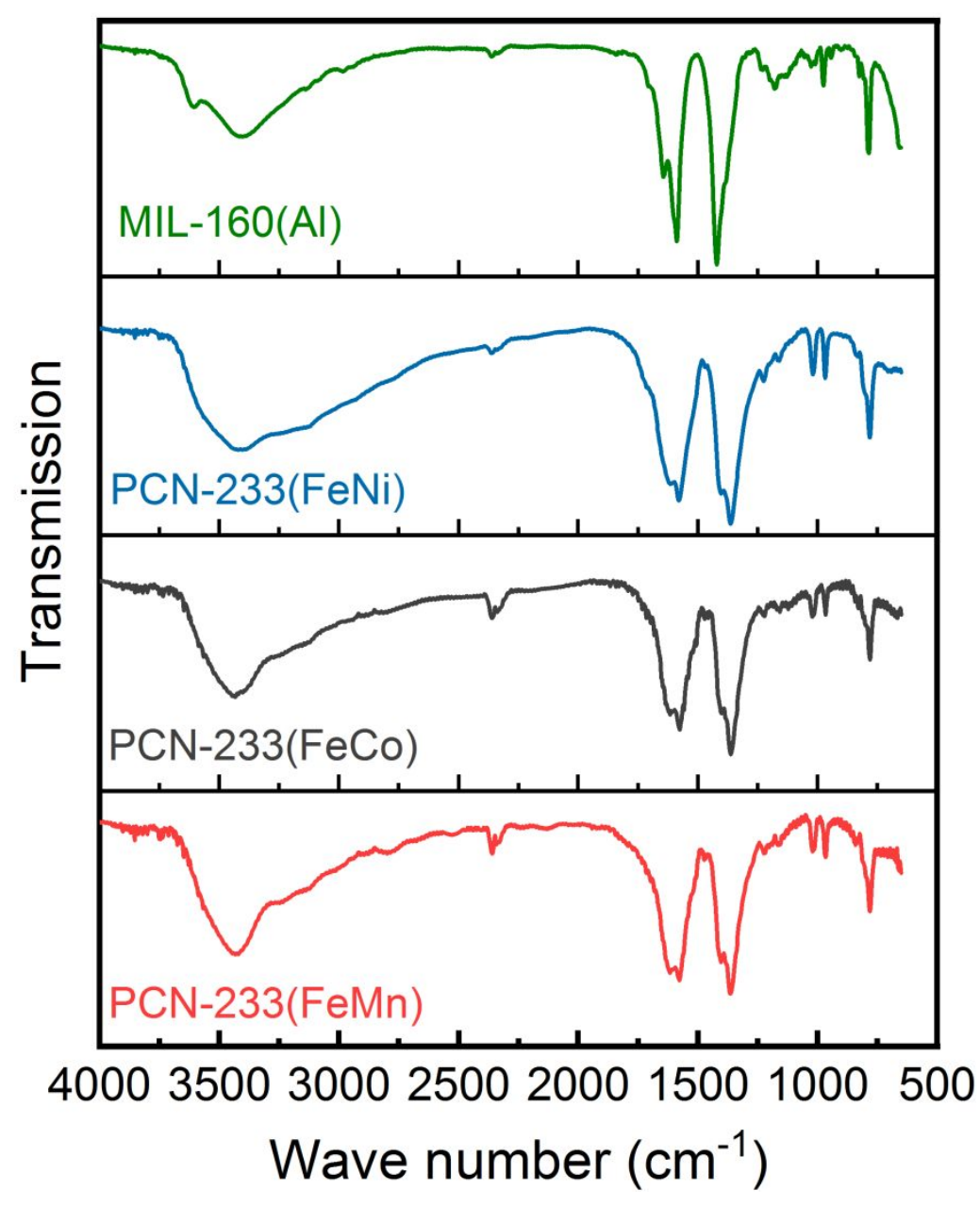

Figure S7 FT-IR spectra of the MOFs studied in this work 


\subsection{Thermal gravimetric analysis}

Thermal gravimetric analysis (TGA) was carried out on NETZSCH STA 449F3 by heating the MOF samples from $30{ }^{\circ} \mathrm{C}$ to $800{ }^{\circ} \mathrm{C}(303 \mathrm{~K}$ to $1073 \mathrm{~K})$ with a heating rate of $5 \mathrm{~K} / \mathrm{min}$ in a dynamic Argon atmosphere.

The first stage of weight loss for MIL-160(Al), occurred before $320{ }^{\circ} \mathrm{C}$, was originated from the removal of surface adsorbed molecules and the guest molecules residual in the frameworks. Similar stages also happened below $250{ }^{\circ} \mathrm{C}$ for $\mathrm{PCN}-$ 233(FeNi) and PCN-233(FeCo), and $240{ }^{\circ} \mathrm{C}$ for PCN-233(FeMn). The next stage, i.e., $350 \sim 500{ }^{\circ} \mathrm{C}$ for MIL-160(Al); 250 350 ${ }^{\circ} \mathrm{C}$ for PCN-233(FeNi) and PCN-233(FeCo); $240 \sim 400{ }^{\circ} \mathrm{C}$ for PCN-233(FeMn), revealed the pyrolysis of ligands and the collapse of the frameworks, by means of the escapes of $\mathrm{CO}_{2}, \mathrm{CO}$ and $\mathrm{H}_{2} \mathrm{O}$ under argon atmosphere.

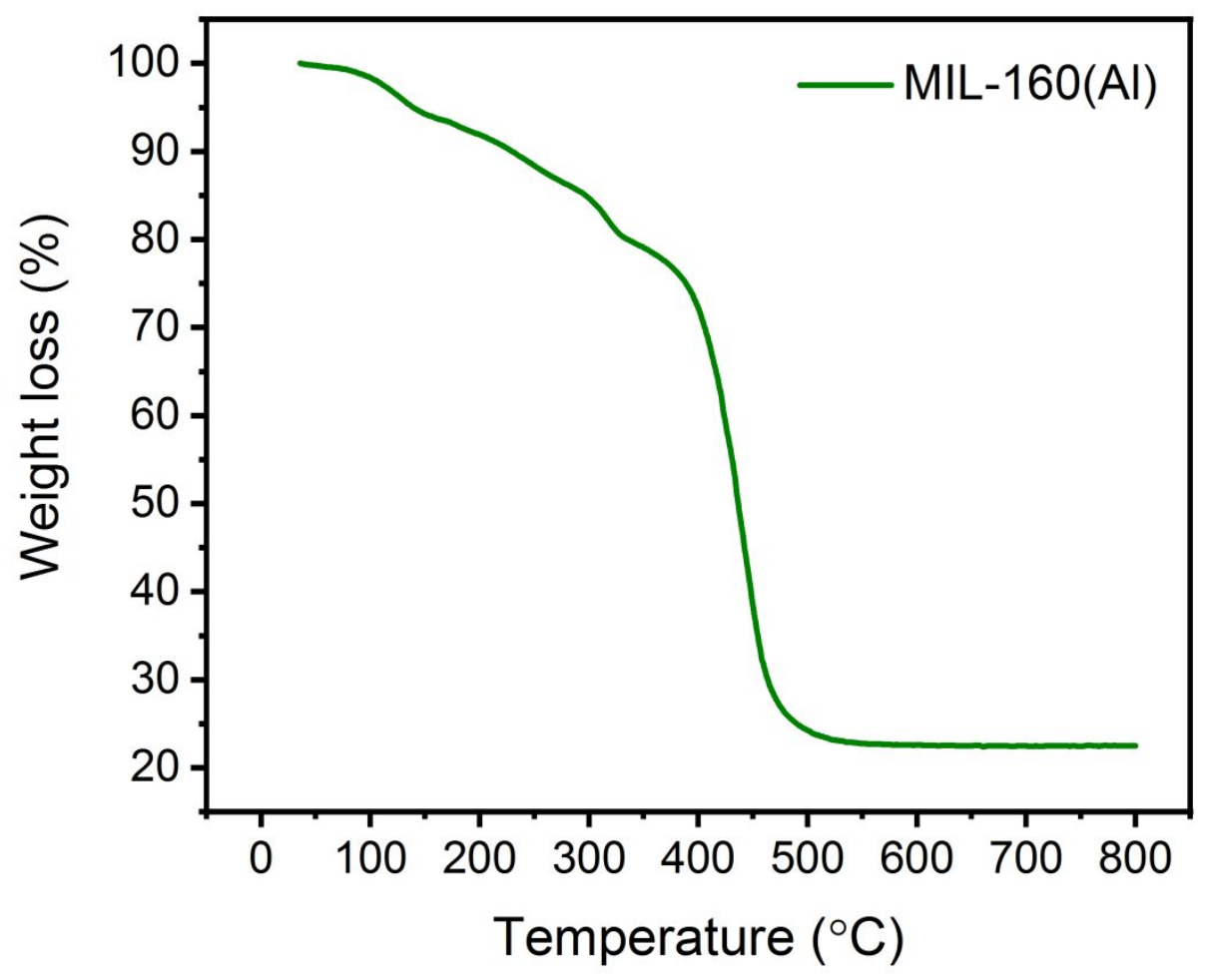

Figure S8 TGA profile for MIL-160(Al) in Ar atmosphere 


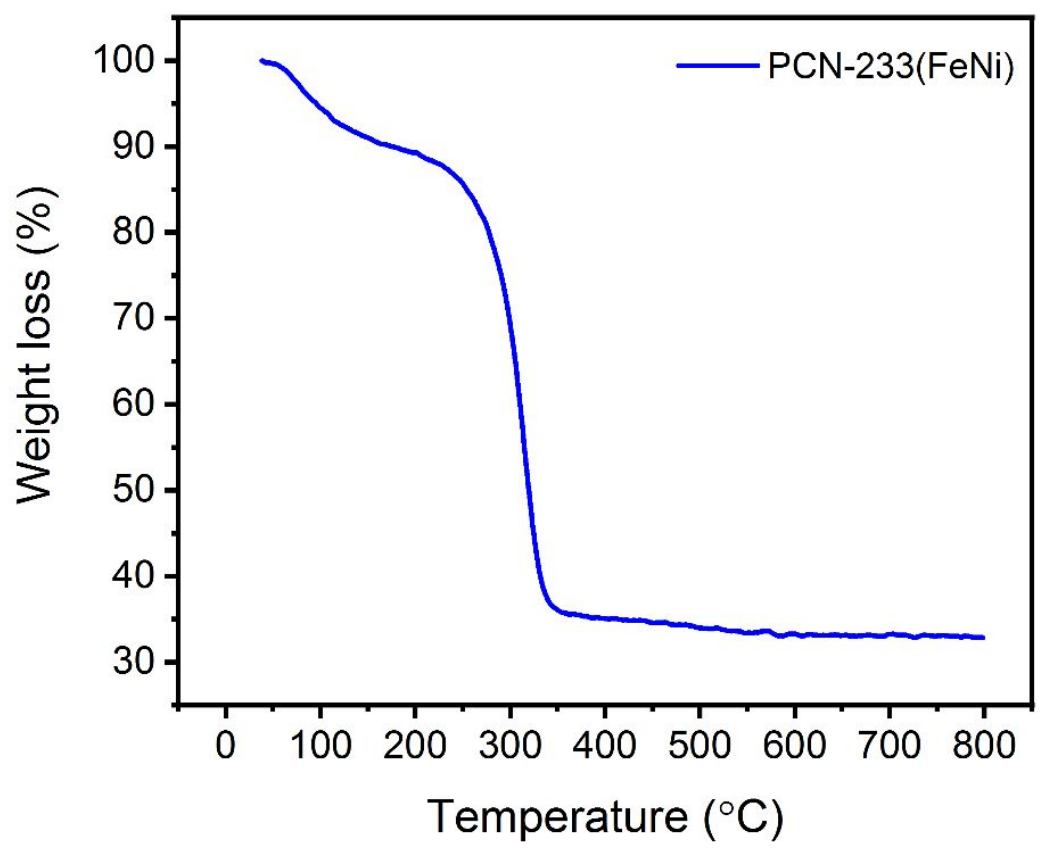

Figure S9 TGA profile for PCN-233(FeNi) in Ar atmosphere

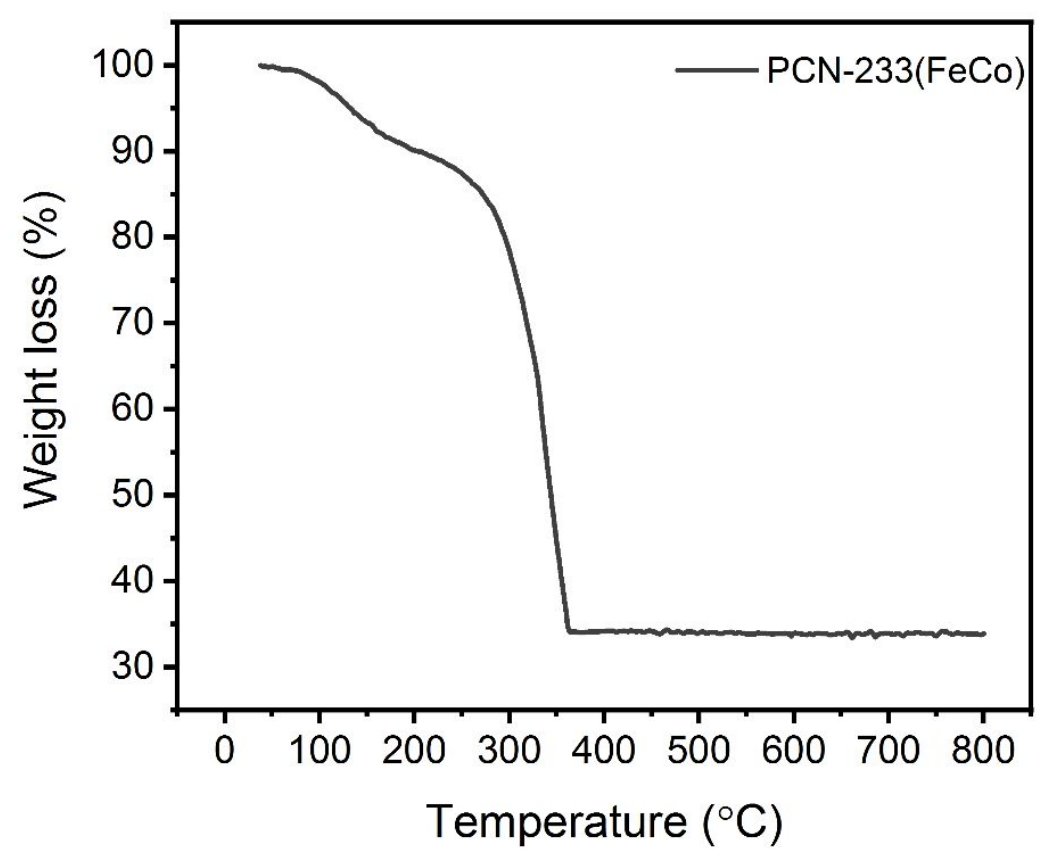

Figure S10 TGA profile for $\mathrm{PCN}-233(\mathrm{FeCo})$ in Ar atmosphere 


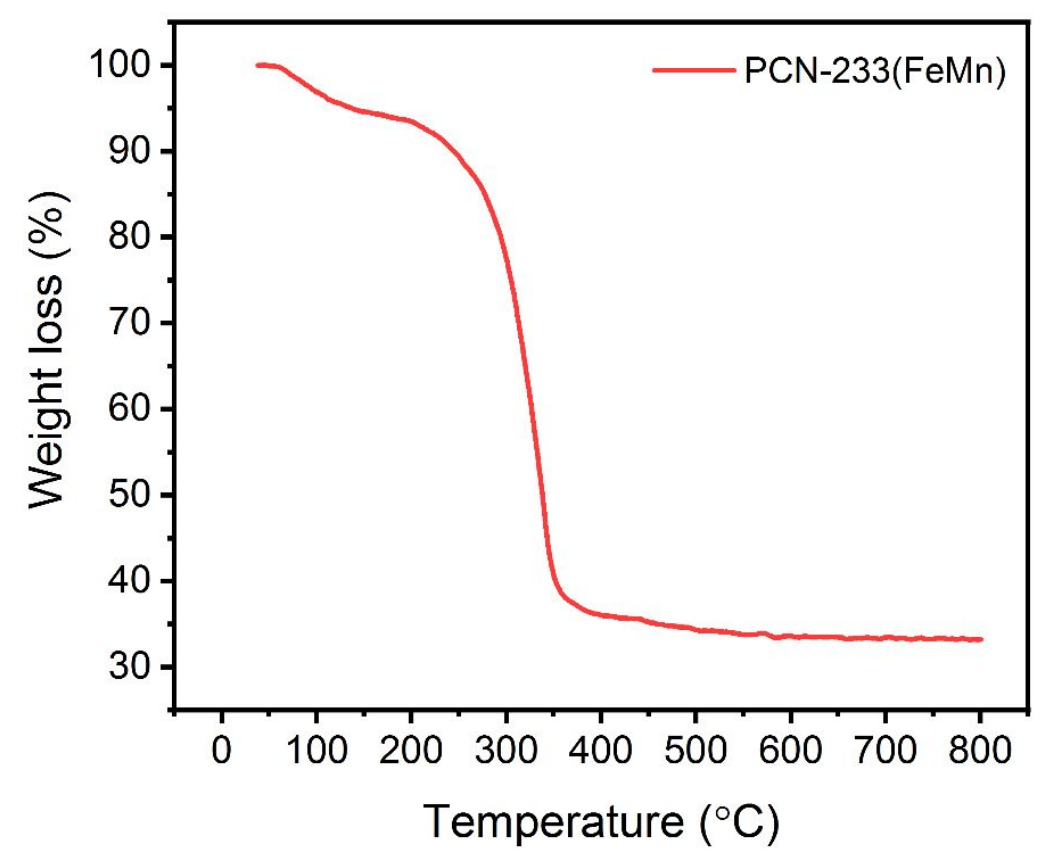

Figure S11 TGA profile for PCN-233(FeMn) in Ar atmosphere 


\subsection{Porosity analysis}

Argon sorption isotherms were performed at $87 \mathrm{~K}$ to study the porosity of assynthesized samples. The linearity of fitting for the Brunauer-Emmett-Teller (BET) surface area were calculated according to the Rouquerol consistency criteria (with a linearity of fitting: $\mathrm{R}>0.99999) ;{ }^{10}$ micropore volume $\left(\mathrm{V}_{\text {mic }}\right)$ was obtained by $t$-Plot method; ${ }^{11}$ total pore volume $\left(\mathrm{V}_{p}\right)$ was obtained by Gurvich-rule at $\mathrm{P} / \mathrm{P}_{0}=0.95 .{ }^{12}$ Pore size distributions (PSD) were calculated with the NLDFT $\operatorname{Ar}(87 \mathrm{~K})$ zeolite kernel based on a cylindrical pore model.

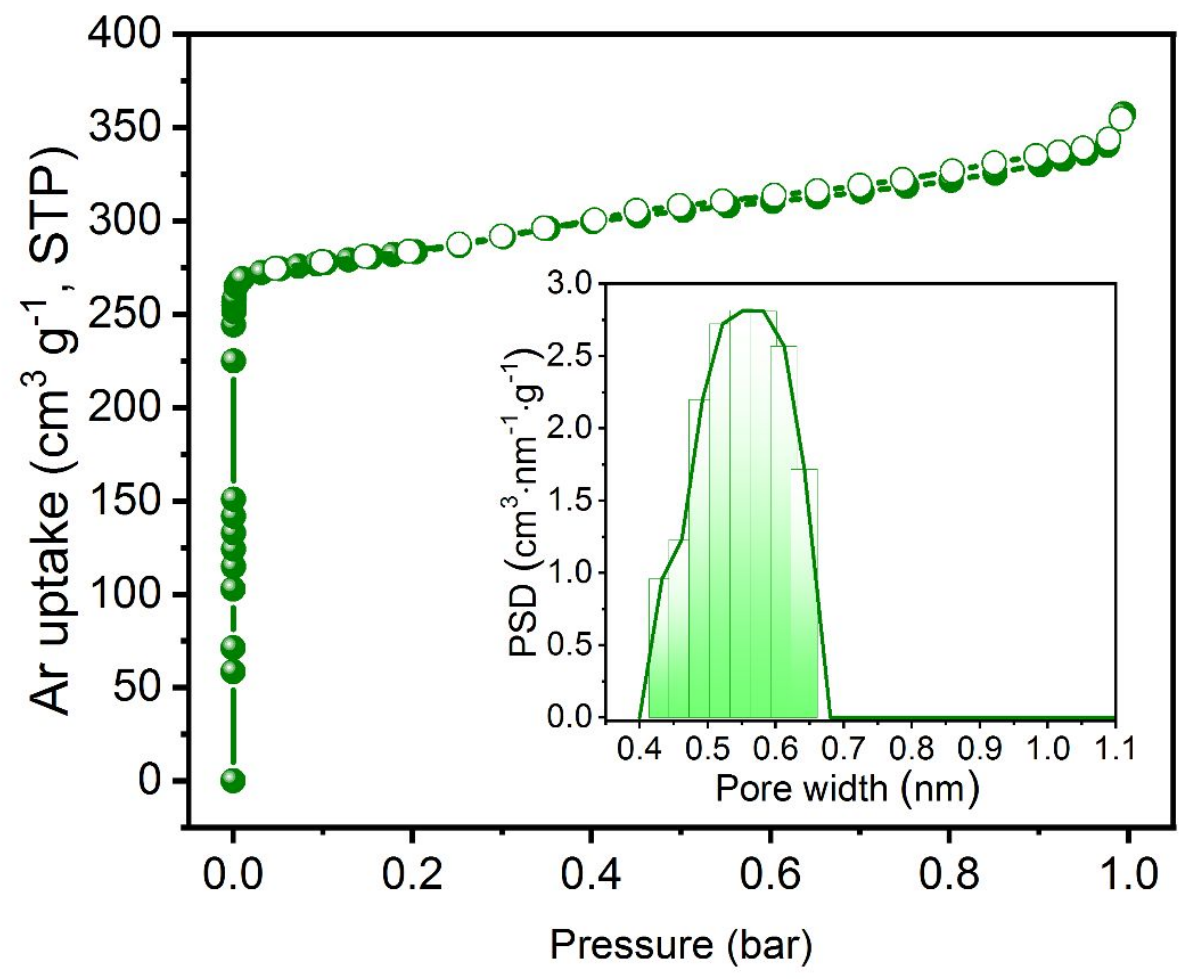

Figure S12 Argon sorption isotherm ( $87 \mathrm{~K}$ ) and pore size distribution (insert) of MIL160 (Al). Solid: adsorption, open: desorption. 


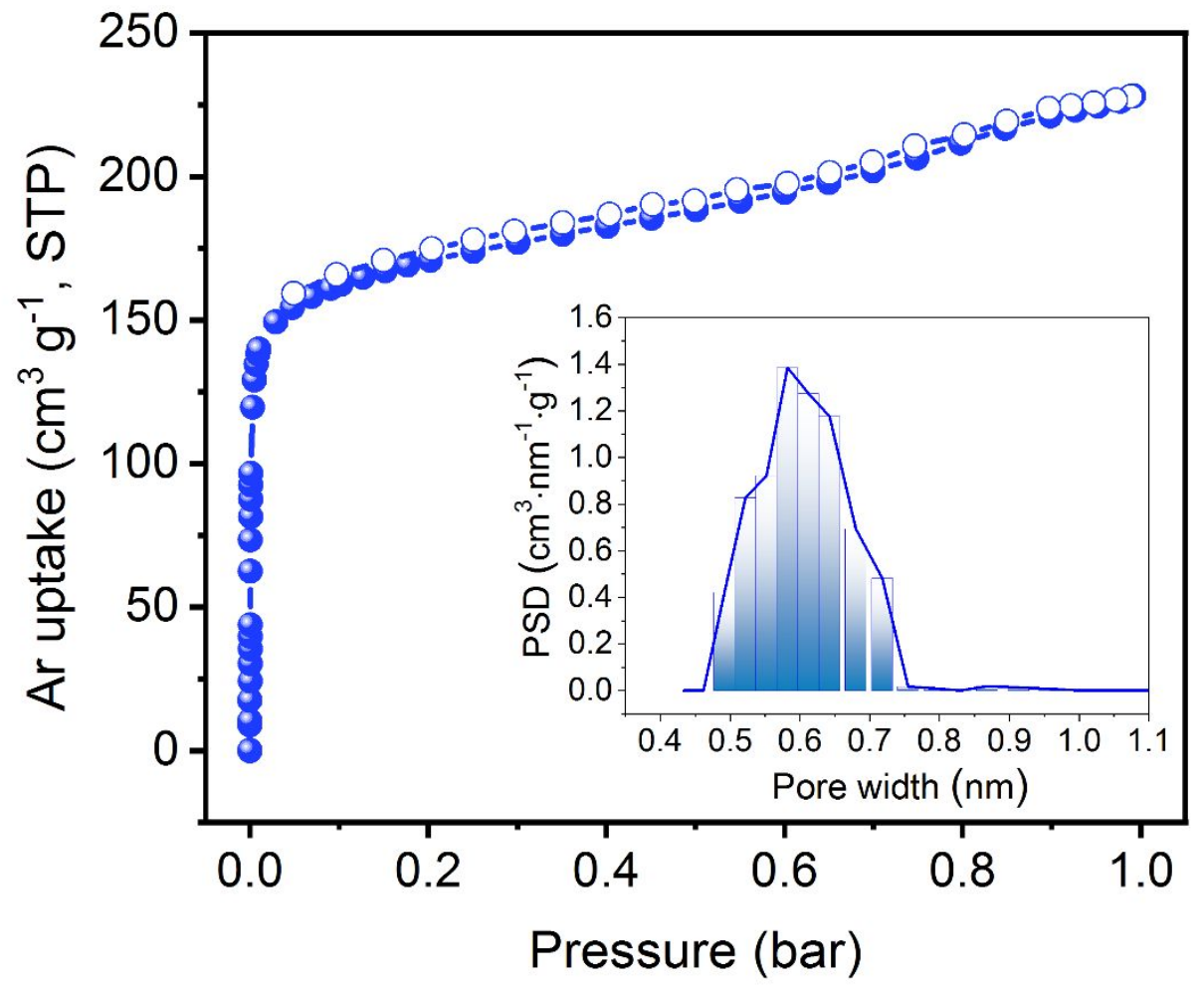

Figure S13 Argon sorption isotherm ( $87 \mathrm{~K})$ and pore size distribution (insert) of PCN233 (FeNi). Solid: adsorption, open: desorption. 


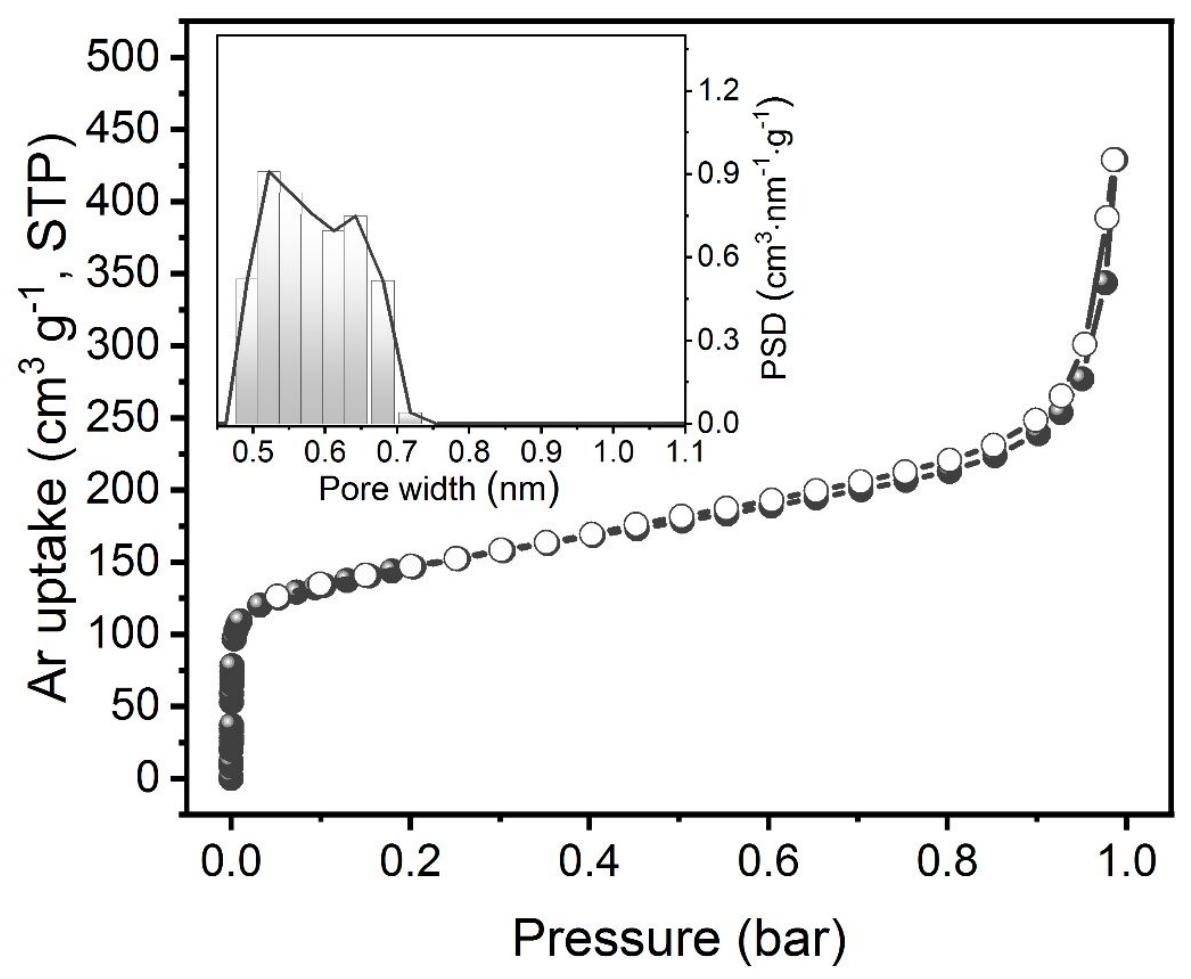

Figure S14 Argon sorption isotherm ( $87 \mathrm{~K})$ and pore size distribution (insert) of PCN233 (FeCo). Solid: adsorption, open: desorption. 


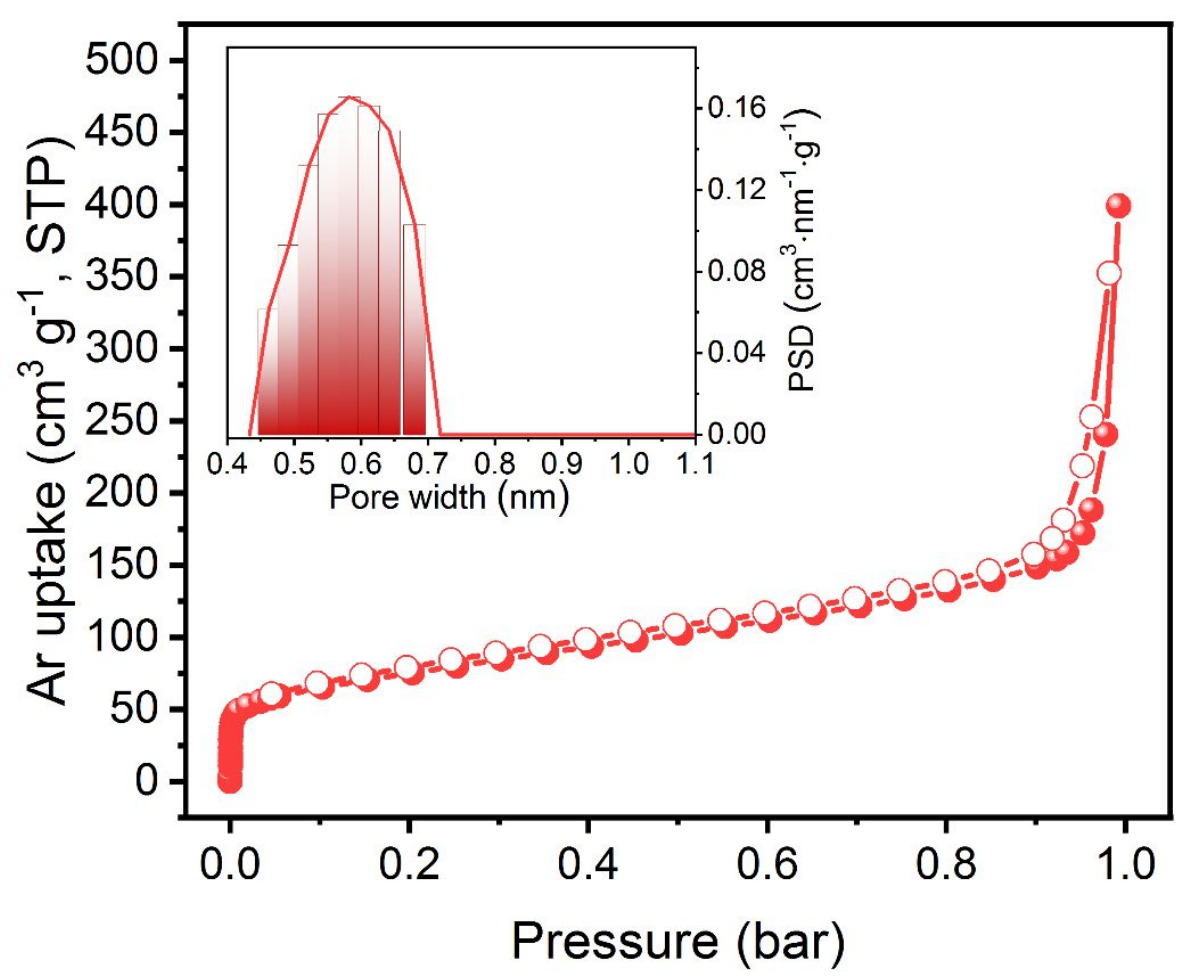

Figure S15 Argon sorption isotherm ( $87 \mathrm{~K})$ and pore size distribution (insert) of PCN233 (FeMn). Solid: adsorption, open: desorption.

Table S1 The textual properties of MOFs calculated from $87 \mathrm{~K}$ Ar adsorption isotherms

\begin{tabular}{c|cccc}
\hline Samples & $\begin{array}{c}\text { MIL-160 } \\
(\mathrm{Al})\end{array}$ & $\begin{array}{c}\text { PCN-233 } \\
(\mathrm{FeNi})\end{array}$ & $\begin{array}{c}\text { PCN-233 } \\
(\mathrm{FeC})\end{array}$ & $\begin{array}{c}\text { PCN-233 } \\
(\mathrm{FeMn})\end{array}$ \\
\hline BET surface area, $\mathrm{m}^{2} \mathrm{~g}^{-1}$ & 1020 & 568 & 463 & 233 \\
Average pore size, $\AA$ & 5.5 & 5.8 & 5.8 & 5.8 \\
Pore volume, $\mathrm{V}_{p}, \mathrm{~cm}^{3} \mathrm{~g}^{-1}$ & 0.43 & 0.29 & 0.35 & 0.22 \\
Micropore volume, $\mathrm{V}_{\text {mic }}, \mathrm{cm}^{3} \mathrm{~g}^{-1}$ & 0.34 & 0.19 & 0.13 & 0.04 \\
\hline
\end{tabular}


(a)

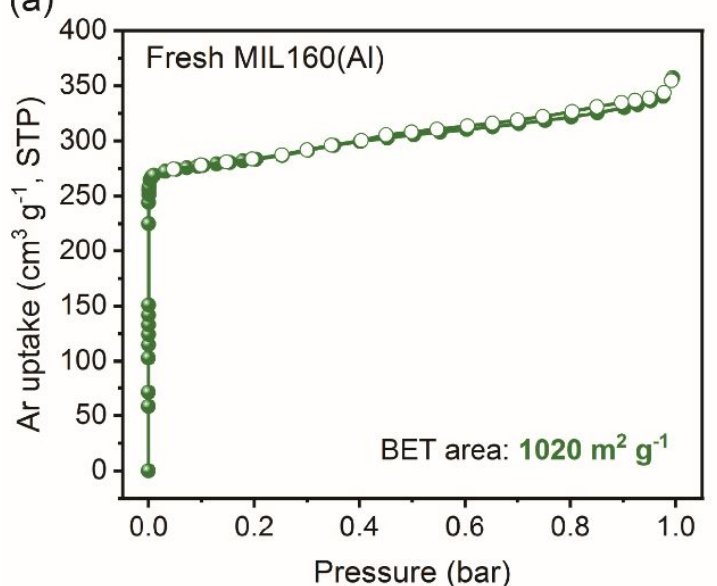

(c)

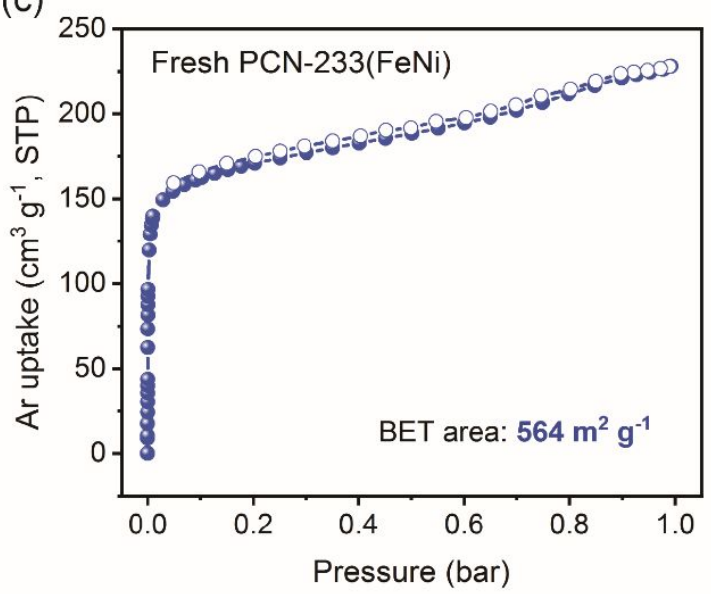

(b)

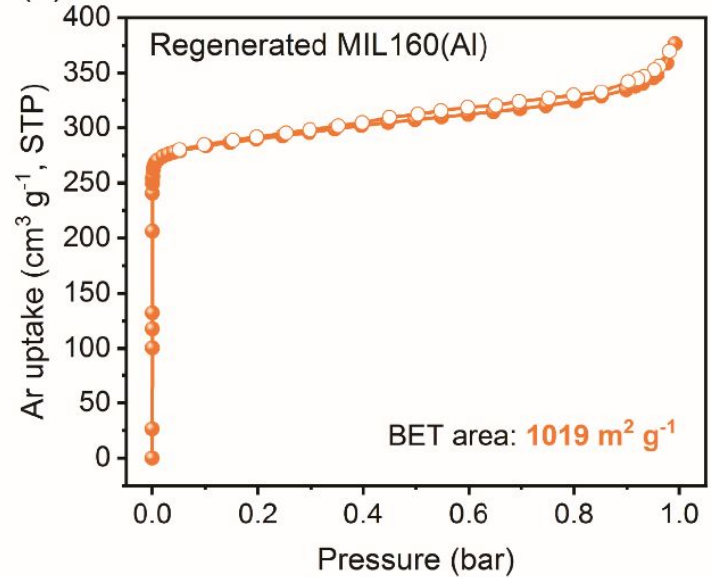

(d)

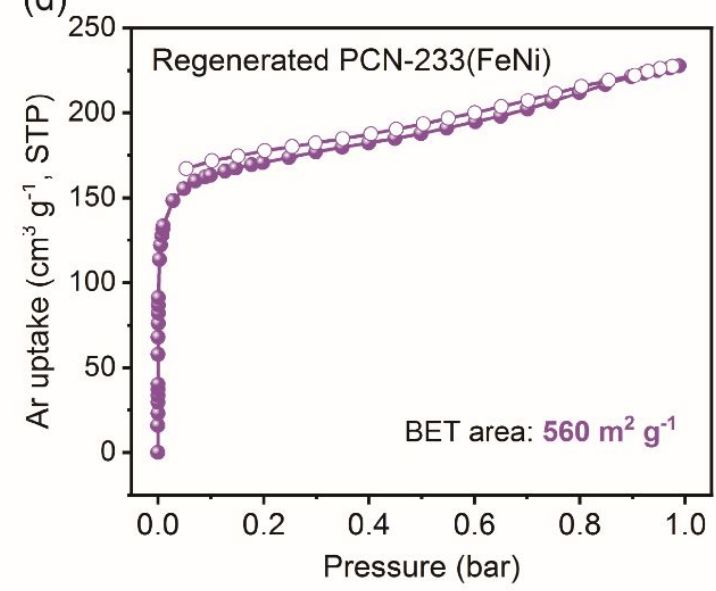

Figure S16 The comparisons of argon adsorption(solid)/desorption (open) isotherms (87 K) of fresh (a) MIL-160(Al), (c) PCN-233(FeNi), and fully regenerated (b) MIL160(Al), and (d) PCN-233(FeNi) samples after water adsorption. 


\subsection{Comparison of MIL-160(Al) produced using different ligands}

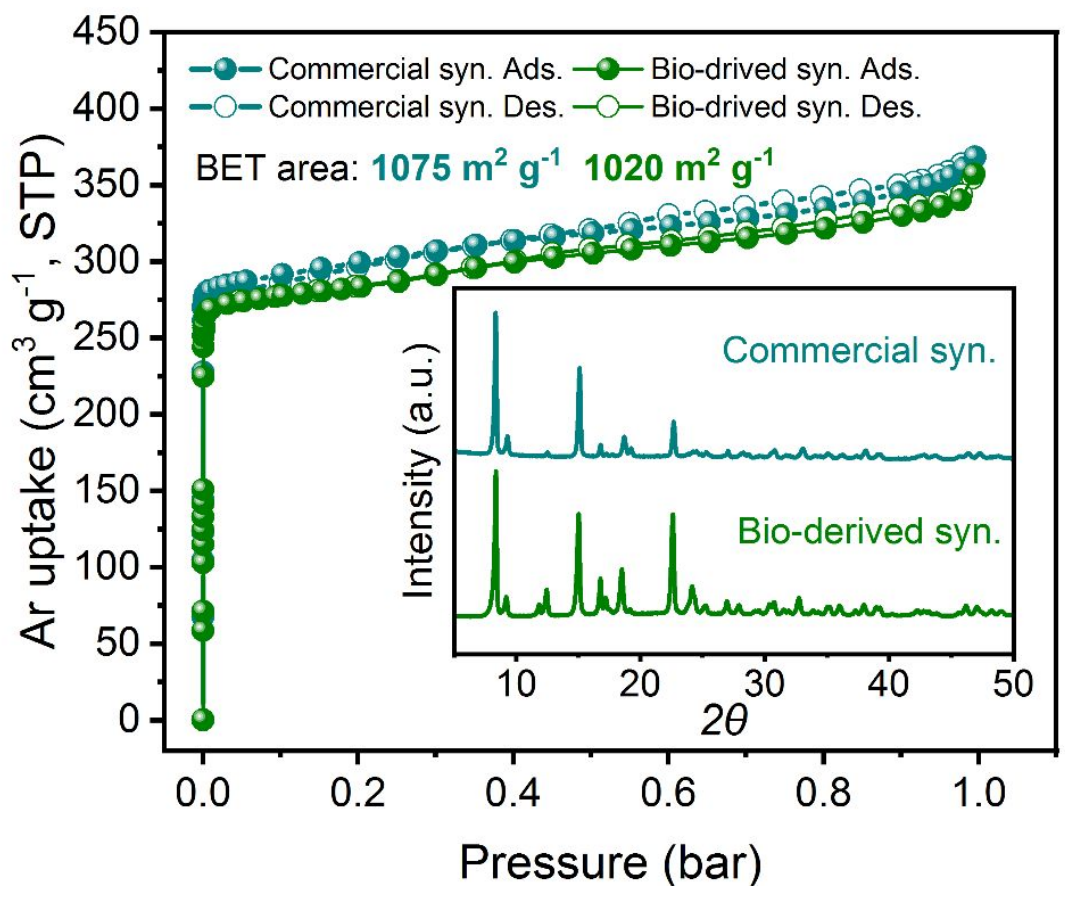

Figure S17 The comparisons of PXRD patterns and argon sorption(solid)/desorption (open) isotherms $(87 \mathrm{~K})$ of MIL-160(Al) synthesized using commercially available and biomass-derived ligands.

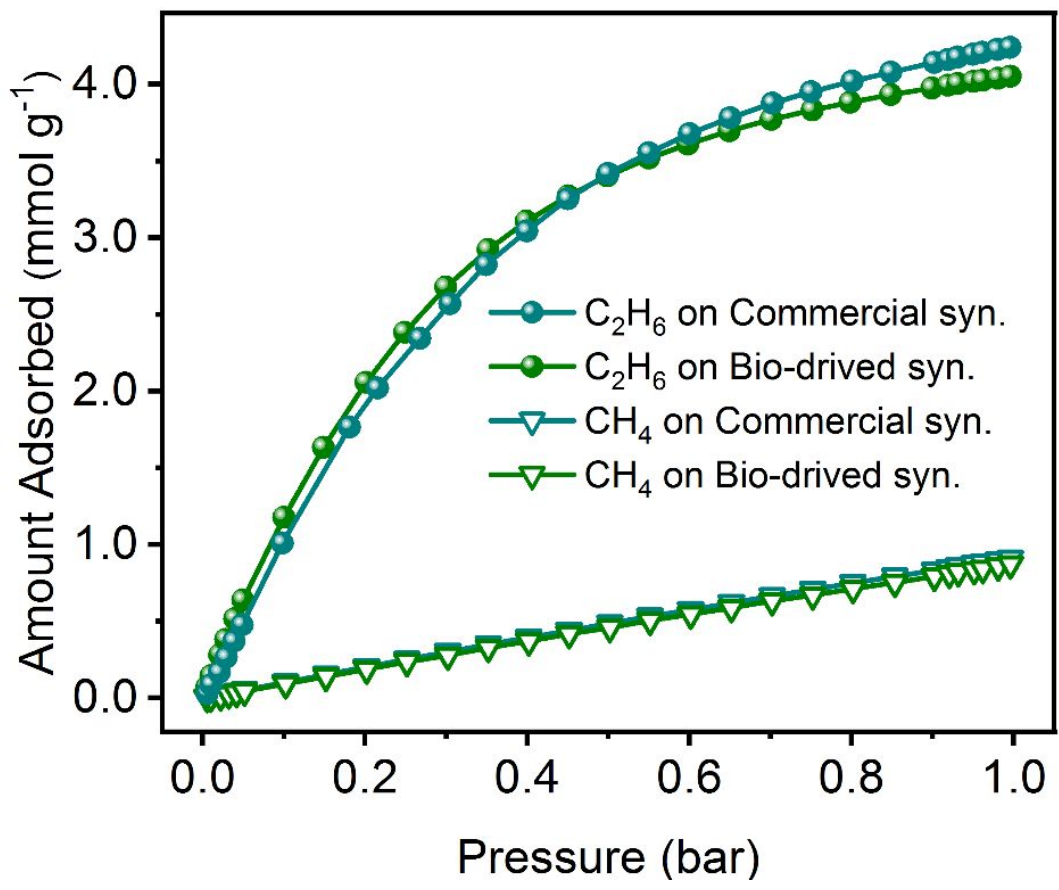

Figure $\mathrm{S18}$ The comparisons of $\mathrm{C}_{2} \mathrm{H}_{6}$ and $\mathrm{CH}_{4}$ adsorption isotherms $(298 \mathrm{~K})$ of MIL160(Al) synthesized using commercially available and biomass-derived ligands. 


\section{Adsorption isotherms, selectivity and heat of adsorption}

\subsection{Gas adsorption isotherms on the renewable MOFs}

Pure gas adsorption isotherms were well-fitted using the dual-site LangmuirFreundlich (DSLF) model: ${ }^{13-14}$

$$
q=q_{1} \frac{b_{1} p^{c_{1}}}{1+b_{1} p^{c_{1}}}+q_{2} \frac{b_{2} p^{c_{2}}}{1+b_{2} p^{c_{2}}}
$$

where $q$ is the gas capacity $\left(\mathrm{mmol} \cdot \mathrm{g}^{-1}\right)$ at gas pressure $(\mathrm{kPa}) ; q_{1}$ and $q_{2}$ are the theoretical maximum gas capacities of the two respective sites $\left(\mathrm{mmol} \cdot \mathrm{g}^{-1}\right) ; b_{1}$ and $b_{2}$ are the affinity coefficients of the two sites $\left(\mathrm{kPa}^{-1}\right) ; c_{1}$ and $c_{2}$ suggest the system heterogeneity of the two sites. ${ }^{15}$

Table S2 DSLF adsorption fitting parameters for MIL-160(Al) at 288, 298 and $308 \mathrm{~K}$.

\begin{tabular}{|c|c|c|c|c|c|c|c|c|}
\hline Temperature (K) & \multicolumn{4}{|c|}{288} & \multicolumn{4}{|c|}{298} \\
\hline Gas & $\mathrm{C}_{2} \mathrm{H}_{6}$ & $\mathrm{CH}_{4}$ & $\mathrm{~N}_{2}$ & $\mathrm{CO}_{2}$ & $\mathrm{C}_{2} \mathrm{H}_{6}$ & $\mathrm{CH}_{4}$ & $\mathrm{~N}_{2}$ & $\mathrm{CO}_{2}$ \\
\hline$q_{\max }$ & 6.2083 & 4.4682 & 2.4688 & 5.9581 & 5.5298 & 2.9989 & 1.6109 & 5.7501 \\
\hline$b$ & 0.0142 & 0.0019 & 0.0009 & 0.0153 & 0.0142 & 0.0019 & 0.0007 & 0.0135 \\
\hline c & 1.1437 & 1.1317 & 1.0681 & 1.1105 & 1.1433 & 1.1492 & 1.0983 & 1.1168 \\
\hline$q_{\max }$ (dual site) & 0.8729 & 0.8695 & 0.8763 & 1.6100 & 0.6709 & 0.8017 & 0.8335 & 0.8815 \\
\hline$b$ (dual site) & 0.0011 & 0.0010 & 0.0009 & 0.0007 & 0.0010 & 0.0009 & 0.0008 & 0.0012 \\
\hline$c($ dual site $)$ & 0.4824 & 0.9813 & 0.9904 & 0.9535 & 0.5018 & 0.9401 & 0.9744 & 0.4878 \\
\hline Temperature (K) & \multicolumn{4}{|c|}{308} & & & & \\
\hline Gas & $\mathrm{C}_{2} \mathrm{H}_{6}$ & $\mathrm{CH}_{4}$ & $\mathrm{~N}_{2}$ & $\mathrm{CO}_{2}$ & & & & \\
\hline$q_{\max }$ & 5.0405 & 2.2234 & 0.5625 & 5.5612 & & & & \\
\hline$b$ & 0.0142 & 0.0019 & 0.0013 & 0.0089 & & & & \\
\hline$c$ & 1.1440 & 1.1406 & 1.1589 & 1.1047 & & & & \\
\hline$q_{\max }($ dual site $)$ & 0.7383 & 0.8651 & 0.4031 & 0.9377 & & & & \\
\hline$b$ (dual site) & 0.0029 & 0.0009 & 0.0012 & 0.0012 & & & & \\
\hline$c$ (dual site) & 0.4445 & 0.9354 & 0.8867 & 0.5527 & & & & \\
\hline
\end{tabular}




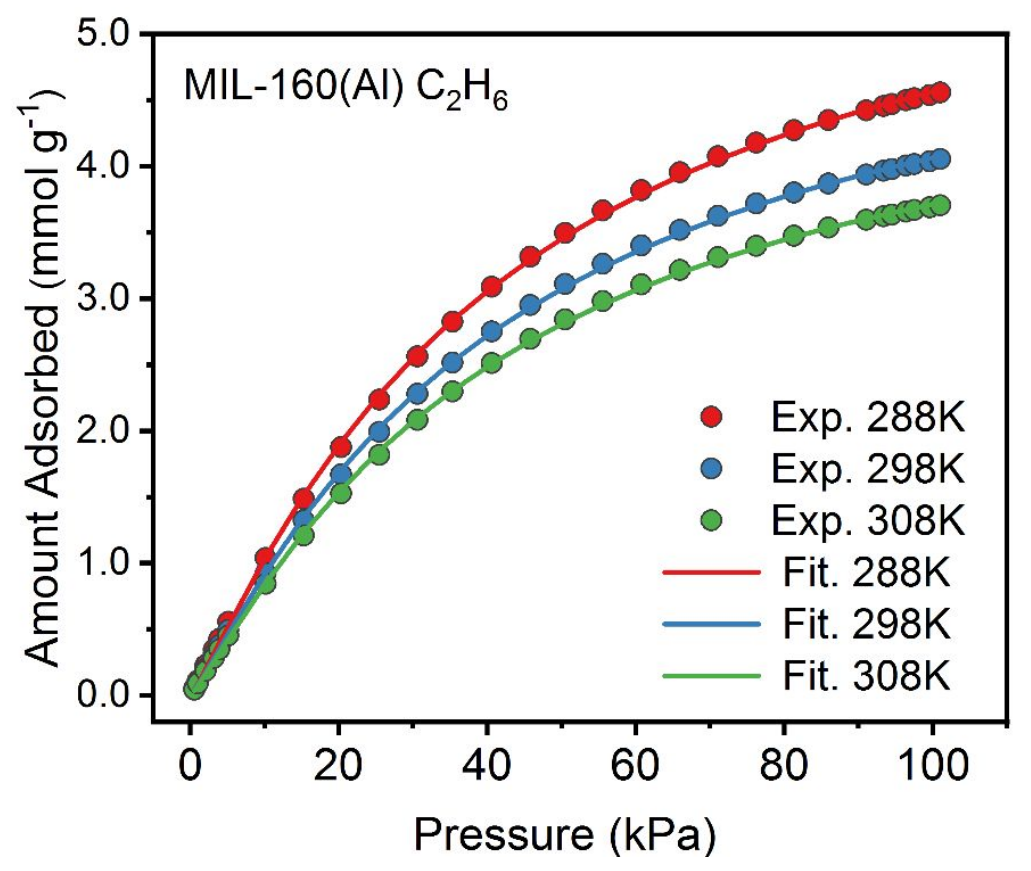

Figure S19 Experimental and DSLF fitting adsorption isotherms of $\mathrm{C}_{2} \mathrm{H}_{6}$ for MIL$160(\mathrm{Al})$ at $288 \mathrm{~K}, 298 \mathrm{~K}$ and $308 \mathrm{~K}$.

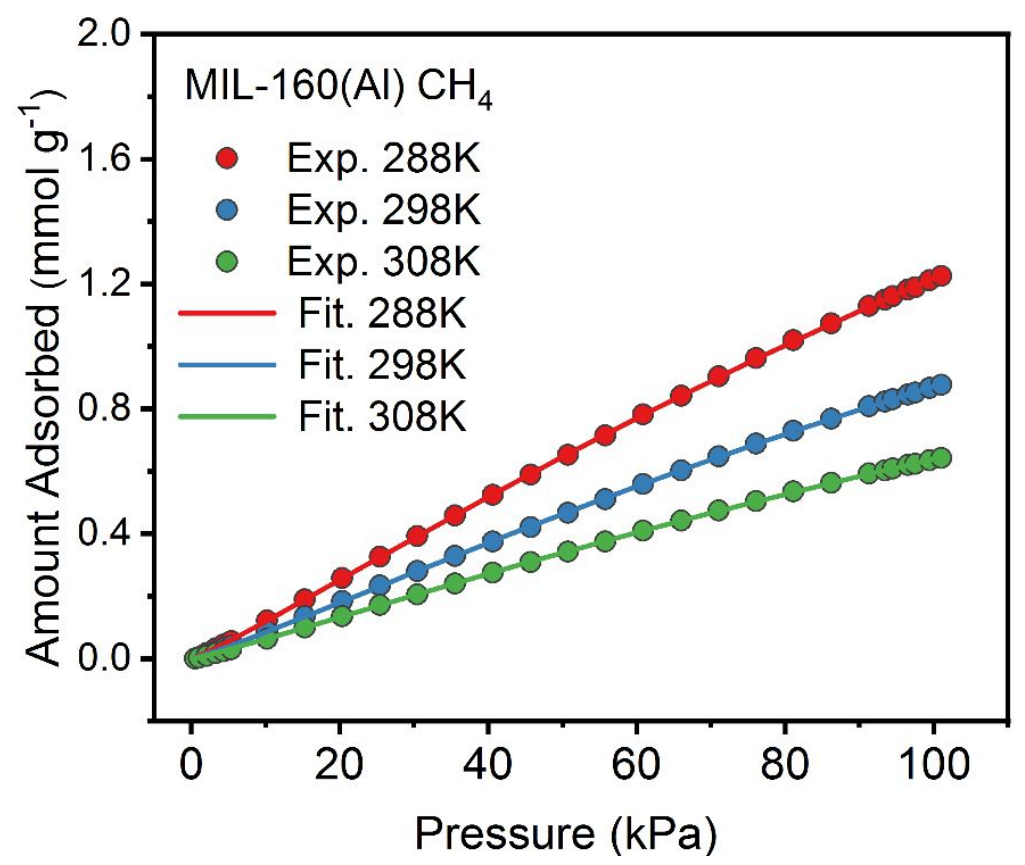

Figure S20 Experimental and DSLF fitting adsorption isotherms of $\mathrm{CH}_{4}$ for MIL$160(\mathrm{Al})$ at $288 \mathrm{~K}, 298 \mathrm{~K}$ and $308 \mathrm{~K}$. 


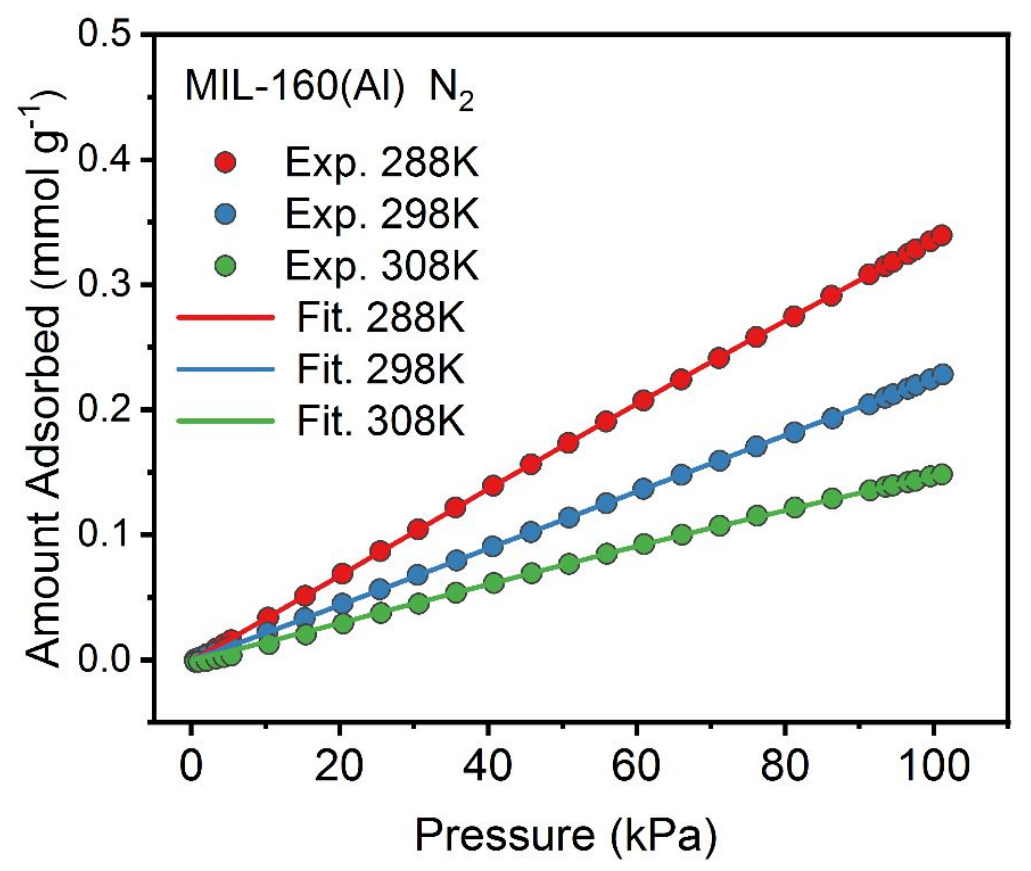

Figure S21 Experimental and DSLF fitting adsorption isotherms of $\mathrm{N}_{2}$ for MIL-160(Al) at $288 \mathrm{~K}, 298 \mathrm{~K}$ and $308 \mathrm{~K}$.

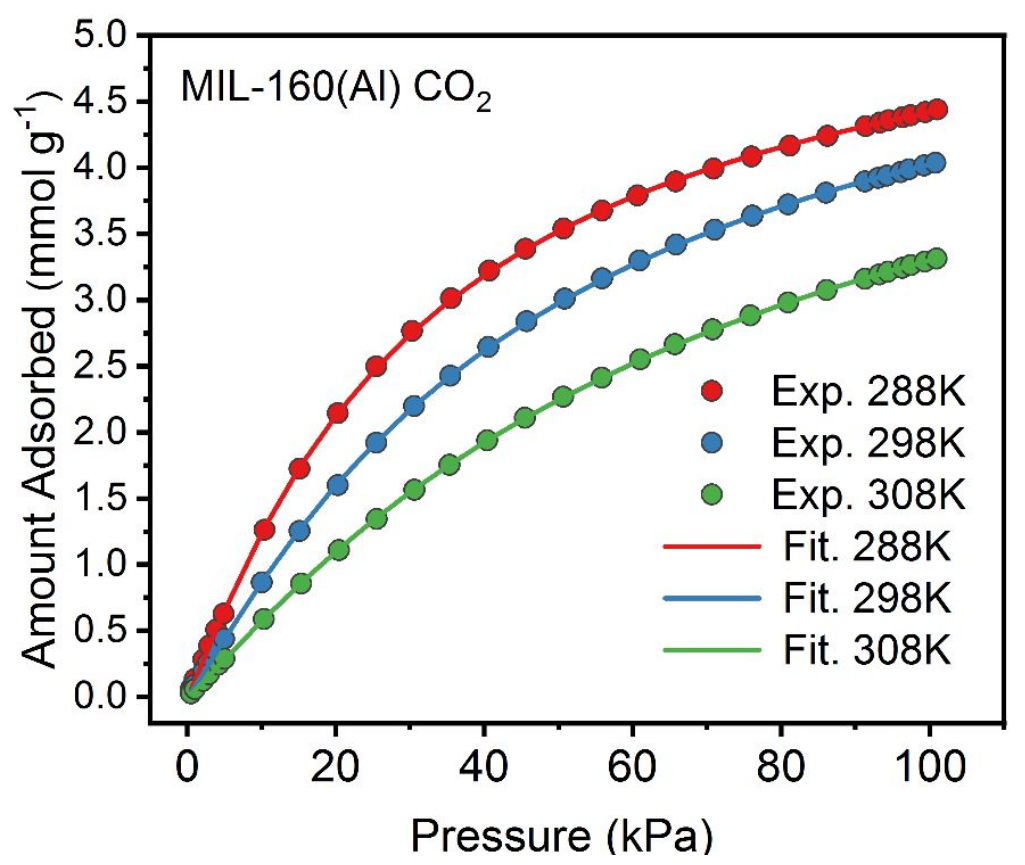

Figure S22 Experimental and DSLF fitting adsorption isotherms of $\mathrm{CO}_{2}$ for MIL$160(\mathrm{Al})$ at $288 \mathrm{~K}, 298 \mathrm{~K}$ and $308 \mathrm{~K}$. 
Table S3 DSLF adsorption fitting parameters for PCN-233(FeNi) at 288 and $298 \mathrm{~K}$.

\begin{tabular}{c|cccc|cccc}
\hline Temperature (K) & \multicolumn{5}{|c|}{288} & \multicolumn{4}{c}{298} \\
\hline Gas & $\mathrm{C}_{2} \mathrm{H}_{6}$ & $\mathrm{CH}_{4}$ & $\mathrm{~N}_{2}$ & $\mathrm{CO}_{2}$ & $\mathrm{C}_{2} \mathrm{H}_{6}$ & $\mathrm{CH}_{4}$ & $\mathrm{~N}_{2}$ & $\mathrm{CO}_{2}$ \\
\hline$q_{\max }$ & 2.8036 & 1.9186 & 0.6344 & 2.7004 & 2.7757 & 1.6160 & 0.4276 & 2.1677 \\
$b$ & 0.0301 & 0.0038 & 0.0013 & 0.0949 & 0.0235 & 0.0027 & 0.0013 & 0.0320 \\
$c$ & 0.9264 & 1.2630 & 1.0666 & 0.8808 & 0.9018 & 1.0092 & 1.0384 & 0.8690 \\
$q_{\text {max }}$ (dual site) & 0.8303 & 3.6771 & 0.9115 & 0.9485 & 0.8965 & 0.8068 & 0.9651 & 1.0338 \\
$b$ (dual site) & 0.0011 & 0.0001 & 0.0009 & 0.0009 & 0.0009 & 0.0008 & 0.0008 & 0.0011 \\
$c$ (dual site) & 0.9527 & 0.9086 & 0.9583 & 0.9501 & 0.9052 & 0.9149 & 0.9335 & 0.9200 \\
\hline
\end{tabular}

Table S4 DSLF adsorption fitting parameters for PCN-233(FeCo) at 288 and $298 \mathrm{~K}$.

\begin{tabular}{c|cccc|cccc}
\hline Temperature (K) & \multicolumn{4}{|c|}{288} & \multicolumn{4}{c}{298} \\
\hline Gas & $\mathrm{C}_{2} \mathrm{H}_{6}$ & $\mathrm{CH}_{4}$ & $\mathrm{~N}_{2}$ & $\mathrm{CO}_{2}$ & $\mathrm{C}_{2} \mathrm{H}_{6}$ & $\mathrm{CH}_{4}$ & $\mathrm{~N}_{2}$ & $\mathrm{CO}_{2}$ \\
\hline$q_{\max }$ & 1.9330 & 1.3434 & 0.0924 & 2.6271 & 1.5480 & 1.0845 & 0.0741 & 1.9089 \\
$b$ & 0.0165 & 0.0012 & 0.0000 & 0.0072 & 0.0158 & 0.0012 & 0.0000 & 0.0063 \\
$c$ & 0.9351 & 1.0442 & 2.6525 & 0.7407 & 0.9494 & 1.0335 & 2.6593 & 0.7409 \\
$q_{\text {max }}$ (dual site) & 0.9421 & 0.9746 & 0.0001 & 0.9348 & 0.7931 & 0.9485 & 0.0095 & 0.8797 \\
$b$ (dual site) & 0.0011 & 0.0009 & 0.0000 & 0.0009 & 0.0008 & 0.0009 & 0.0000 & 0.0009 \\
$c$ (dual site) & 0.4554 & 0.9918 & 0.0026 & 0.8116 & 0.6439 & 0.9777 & 0.0428 & 0.7710 \\
\hline
\end{tabular}

Table S5 DSLF adsorption fitting parameters for PCN-233(FeMn) at 288 and $298 \mathrm{~K}$.

\begin{tabular}{c|cccc|cccc}
\hline Temperature $(\mathrm{K})$ & \multicolumn{4}{|c|}{288} & \multicolumn{4}{c}{298} \\
\hline Gas & $\mathrm{C}_{2} \mathrm{H}_{6}$ & $\mathrm{CH}_{4}$ & $\mathrm{~N}_{2}$ & $\mathrm{CO}_{2}$ & $\mathrm{C}_{2} \mathrm{H}_{6}$ & $\mathrm{CH}_{4}$ & $\mathrm{~N}_{2}$ & $\mathrm{CO}_{2}$ \\
\hline$q_{\max }$ & 2.8024 & 2.2060 & 0.1111 & 3.2601 & 2.3195 & 1.8964 & 0.0957 & 2.6072 \\
$b$ & 0.0190 & 0.0012 & 0.0000 & 0.0463 & 0.0191 & 0.0011 & 0.0000 & 0.0263 \\
$c$ & 0.9039 & 1.0143 & 2.4270 & 0.8732 & 0.9071 & 1.0013 & 2.3809 & 0.7417 \\
$q_{\text {max }}$ (dual site) & 0.9231 & 1.0969 & 0.0489 & 0.9522 & 0.8640 & 1.2867 & 0.0000 & 0.9323 \\
$b$ (dual site) & 0.0008 & 0.0009 & 0.0000 & 0.0010 & 0.0010 & 0.0009 & 0.0000 & 0.0009 \\
$c$ (dual site) & 0.9014 & 0.9971 & 0.2428 & 0.8845 & 0.8928 & 0.9832 & 0.0001 & 0.7864 \\
\hline
\end{tabular}




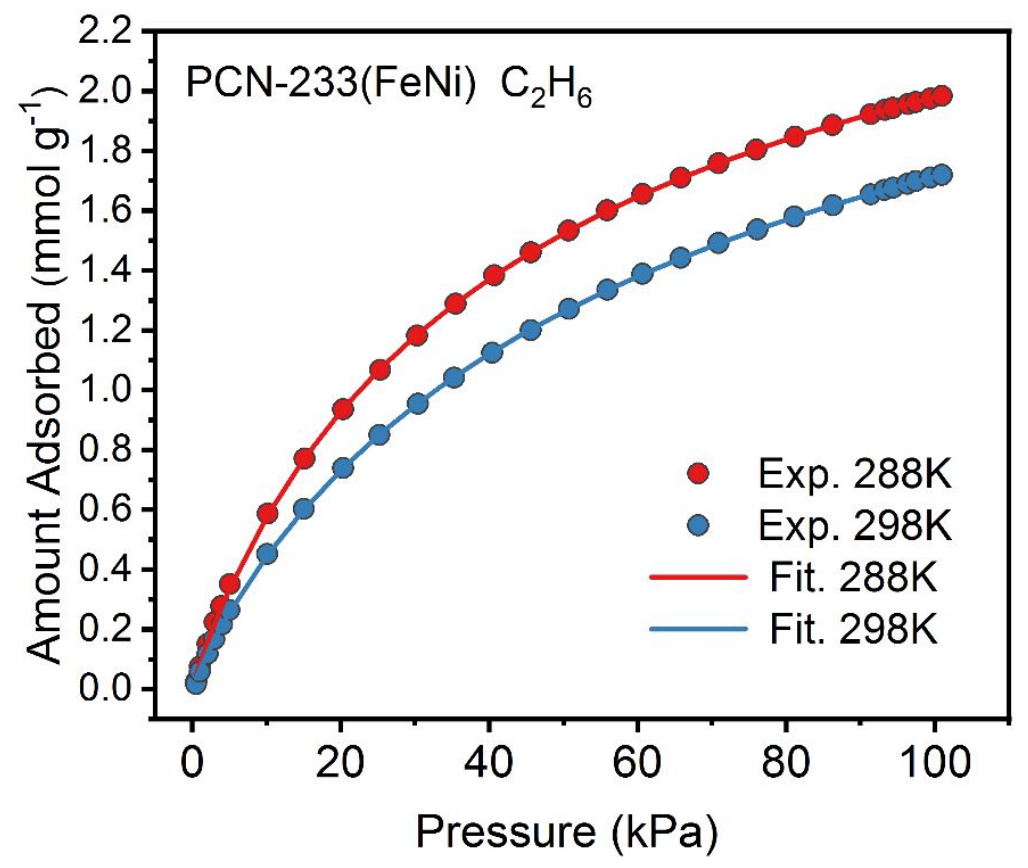

Figure S23 Experimental and DSLF fitting adsorption isotherms of $\mathrm{C}_{2} \mathrm{H}_{6}$ for PCN$233(\mathrm{FeNi})$ at $288 \mathrm{~K}$ and $298 \mathrm{~K}$.

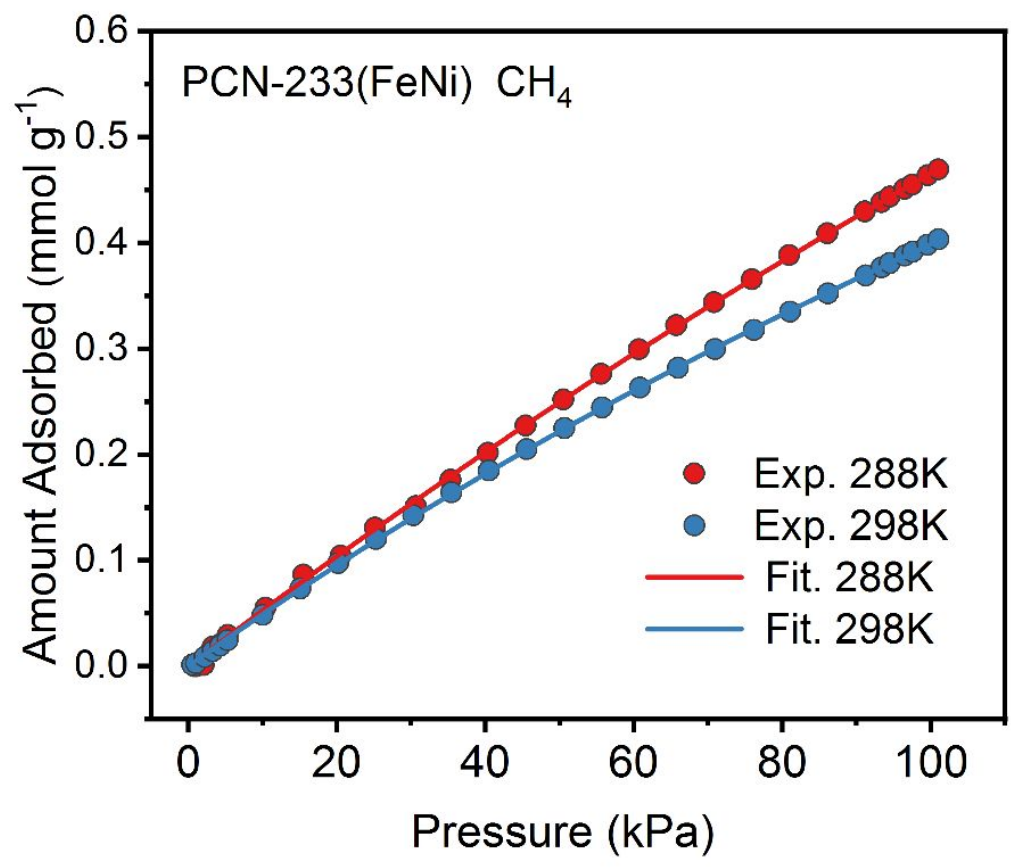

Figure S24 Experimental and DSLF fitting adsorption isotherms of $\mathrm{CH}_{4}$ for $\mathrm{PCN}$ $233(\mathrm{FeNi})$ at $288 \mathrm{~K}$ and $298 \mathrm{~K}$. 


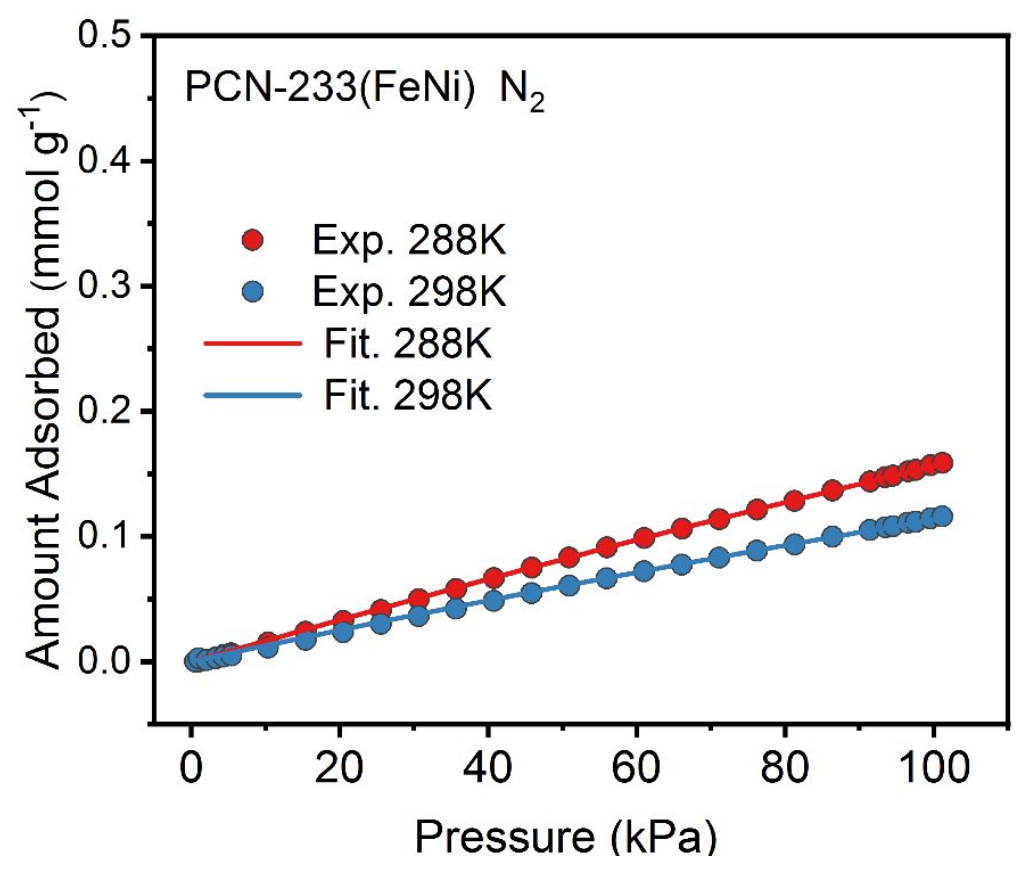

Figure S25 Experimental and DSLF fitting adsorption isotherms of $\mathrm{N}_{2}$ for PCN$233(\mathrm{FeNi})$ at $288 \mathrm{~K}$ and $298 \mathrm{~K}$.

The gas adsorption uptakes on PCN-233 MOFs at $308 \mathrm{~K}$ were too low to be accurate, thus the corresponding isotherms were not included.

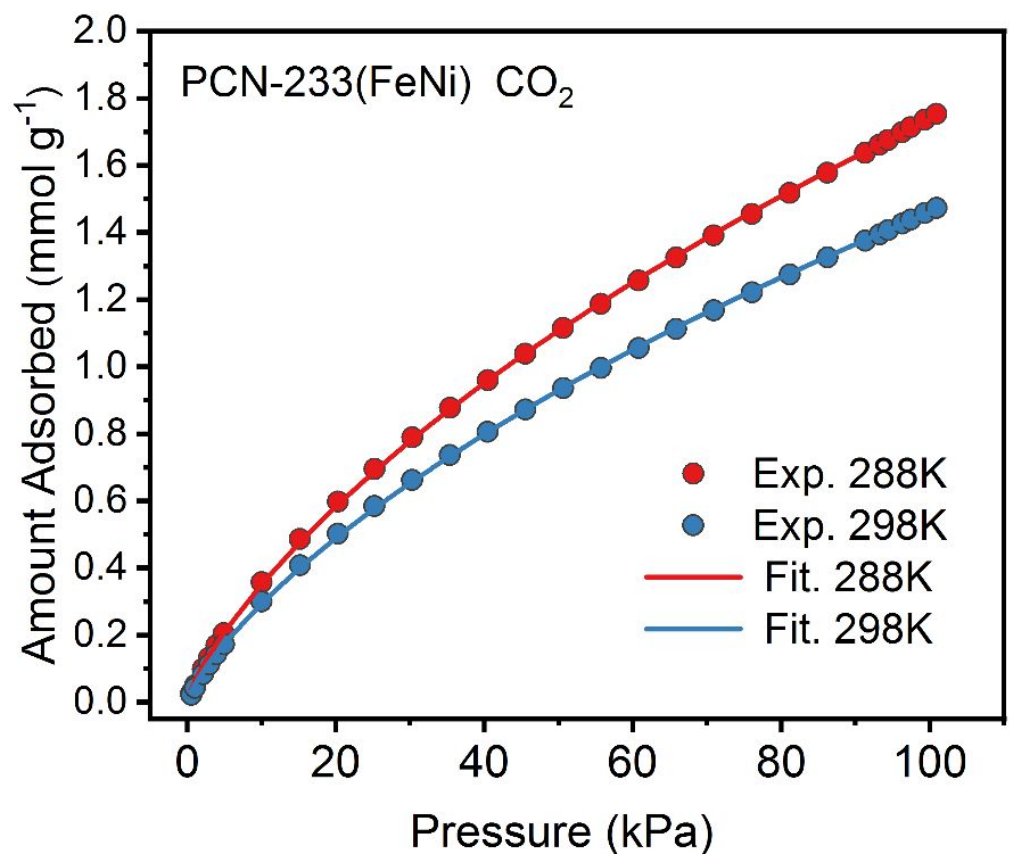

Figure S26 Experimental and DSLF fitting adsorption isotherms of $\mathrm{CO}_{2}$ for PCN$233(\mathrm{FeNi})$ at $288 \mathrm{~K}$ and $298 \mathrm{~K}$. 


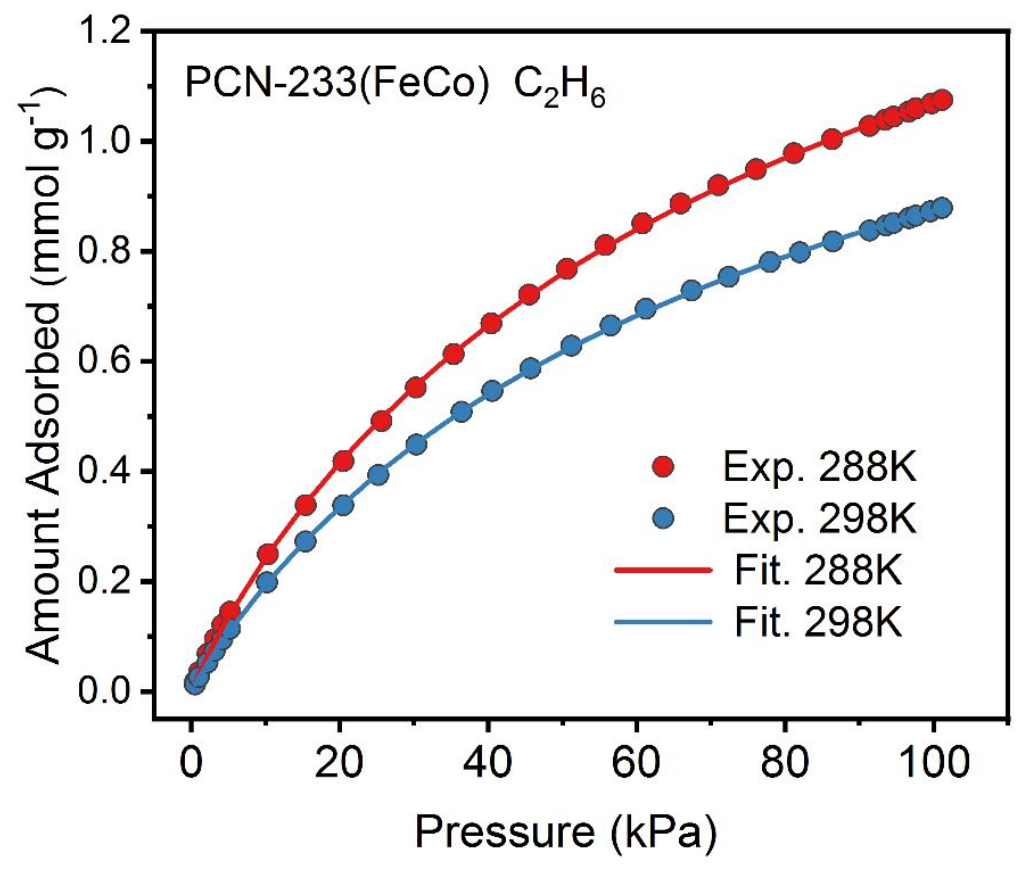

Figure S27 Experimental and DSLF fitting adsorption isotherms of $\mathrm{C}_{2} \mathrm{H}_{6}$ for PCN$233(\mathrm{FeCo})$ at $288 \mathrm{~K}$ and $298 \mathrm{~K}$.

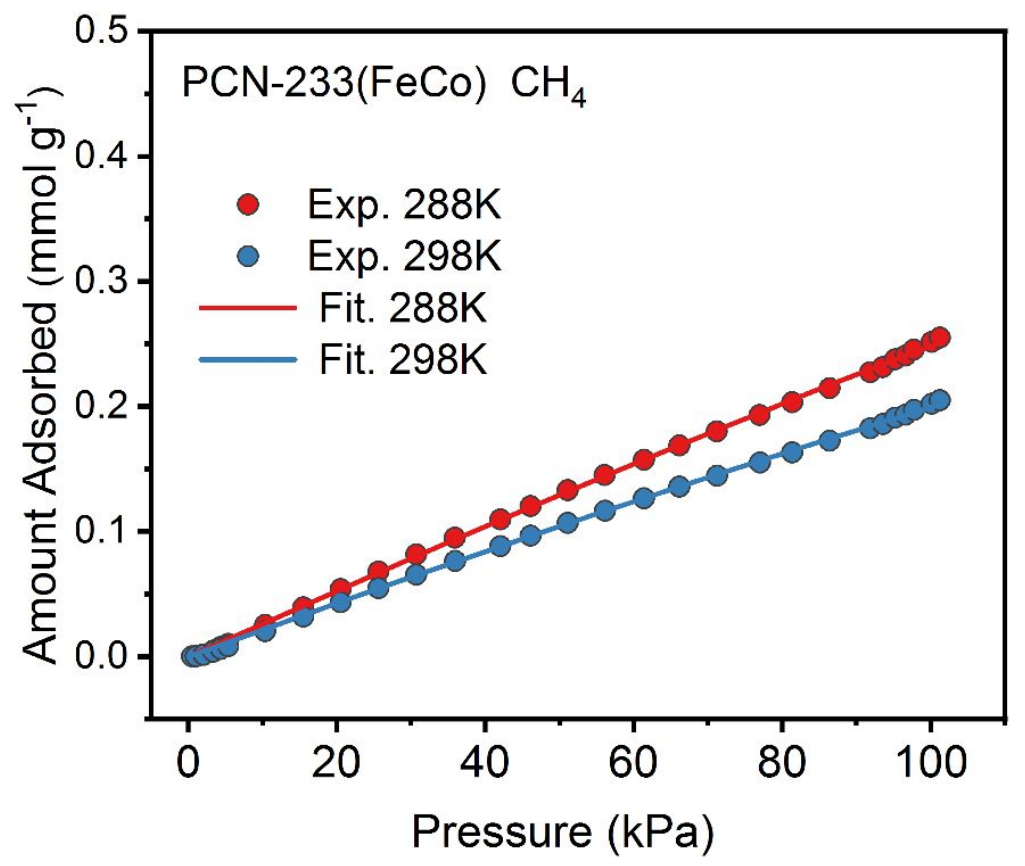

Figure S28 Experimental and DSLF fitting adsorption isotherms of $\mathrm{CH}_{4}$ for $\mathrm{PCN}$ $233(\mathrm{FeCo})$ at $288 \mathrm{~K}$ and $298 \mathrm{~K}$. 


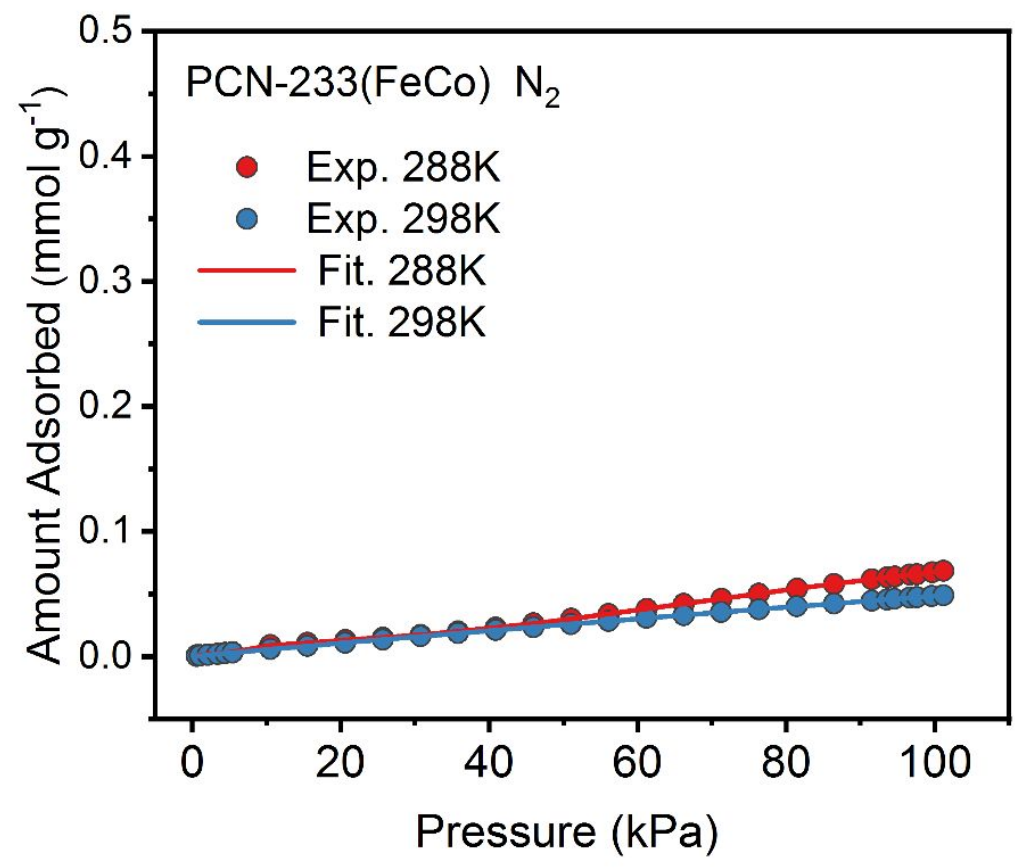

Figure S29 Experimental and DSLF fitting adsorption isotherms of $\mathrm{N}_{2}$ for PCN$233(\mathrm{FeCo})$ at $288 \mathrm{~K}$ and $298 \mathrm{~K}$.

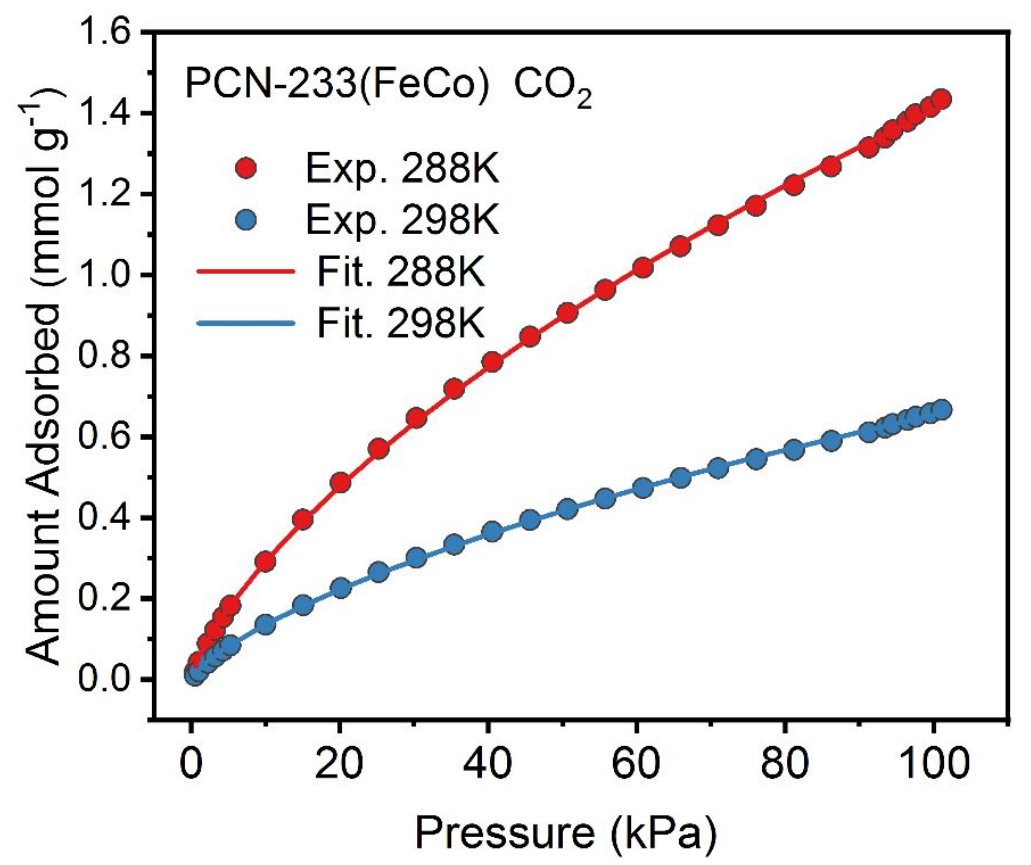

Figure S30 Experimental and DSLF fitting adsorption isotherms of $\mathrm{CO}_{2}$ for PCN$233(\mathrm{FeCo})$ at $288 \mathrm{~K}$ and $298 \mathrm{~K}$. 


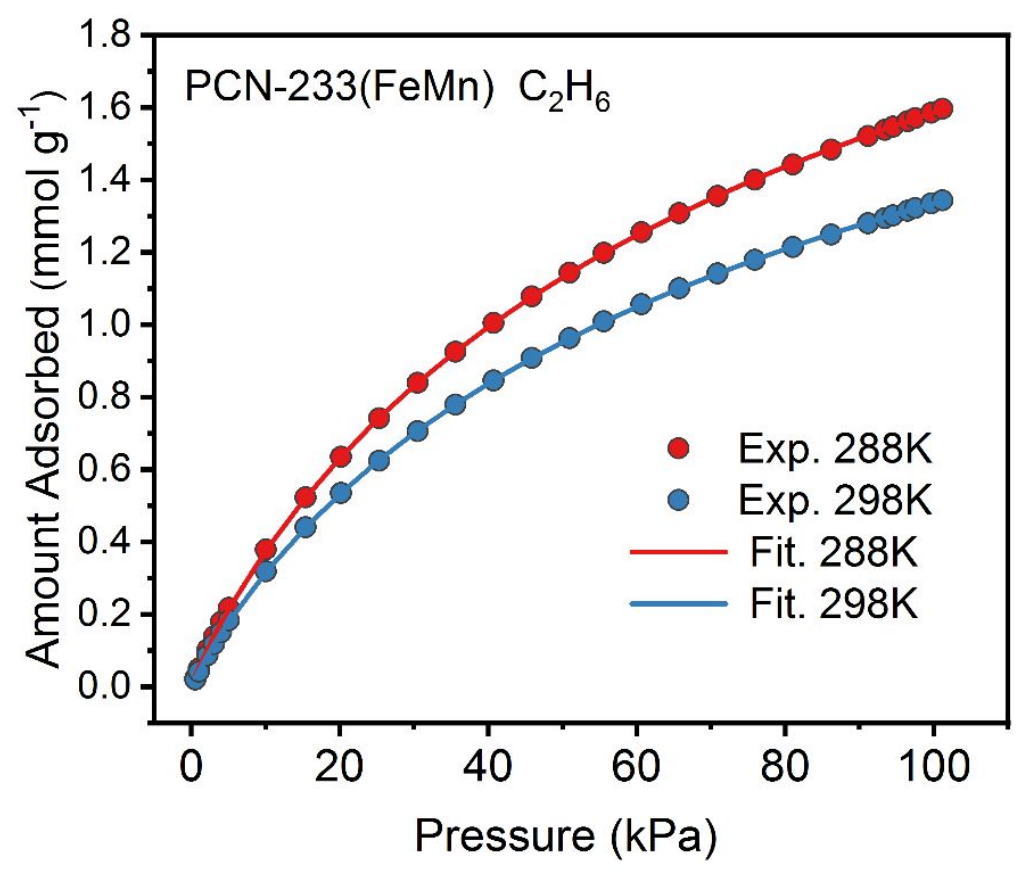

Figure S31 Experimental and DSLF fitting adsorption isotherms of $\mathrm{C}_{2} \mathrm{H}_{6}$ for PCN$233(\mathrm{FeMn})$ at $288 \mathrm{~K}$ and $298 \mathrm{~K}$.

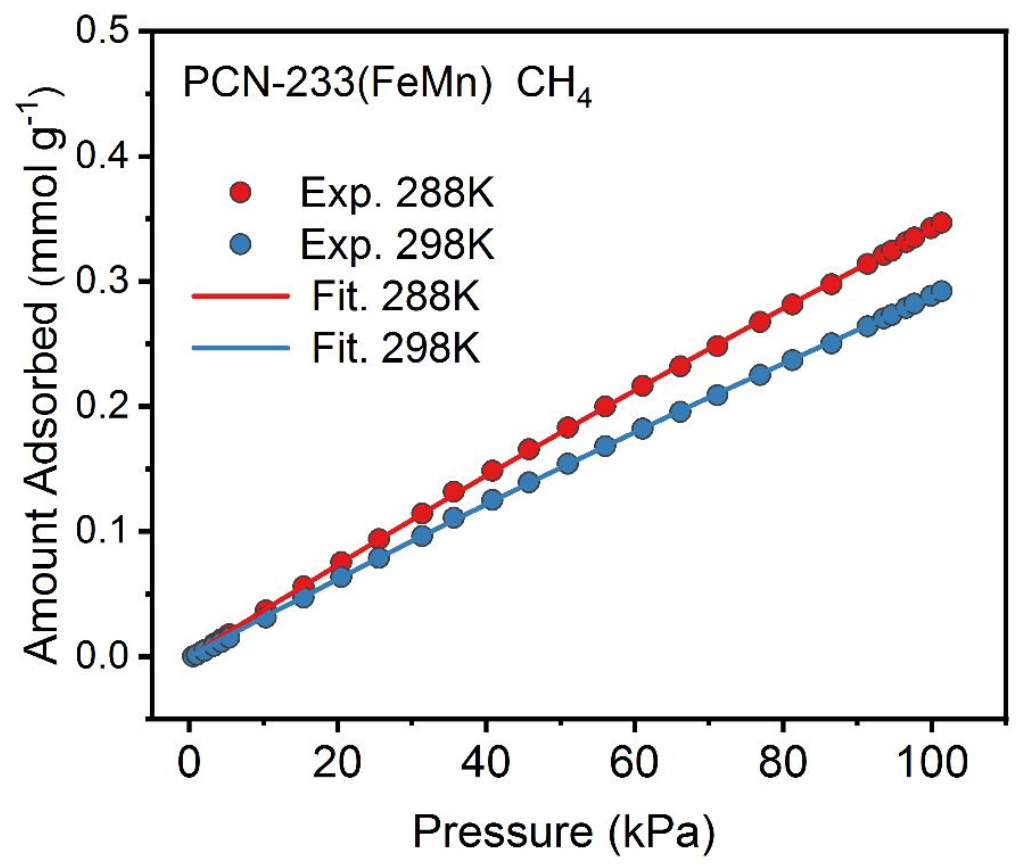

Figure S32 Experimental and DSLF fitting adsorption isotherms of $\mathrm{CH}_{4}$ for $\mathrm{PCN}$ $233(\mathrm{FeMn})$ at $288 \mathrm{~K}$ and $298 \mathrm{~K}$. 


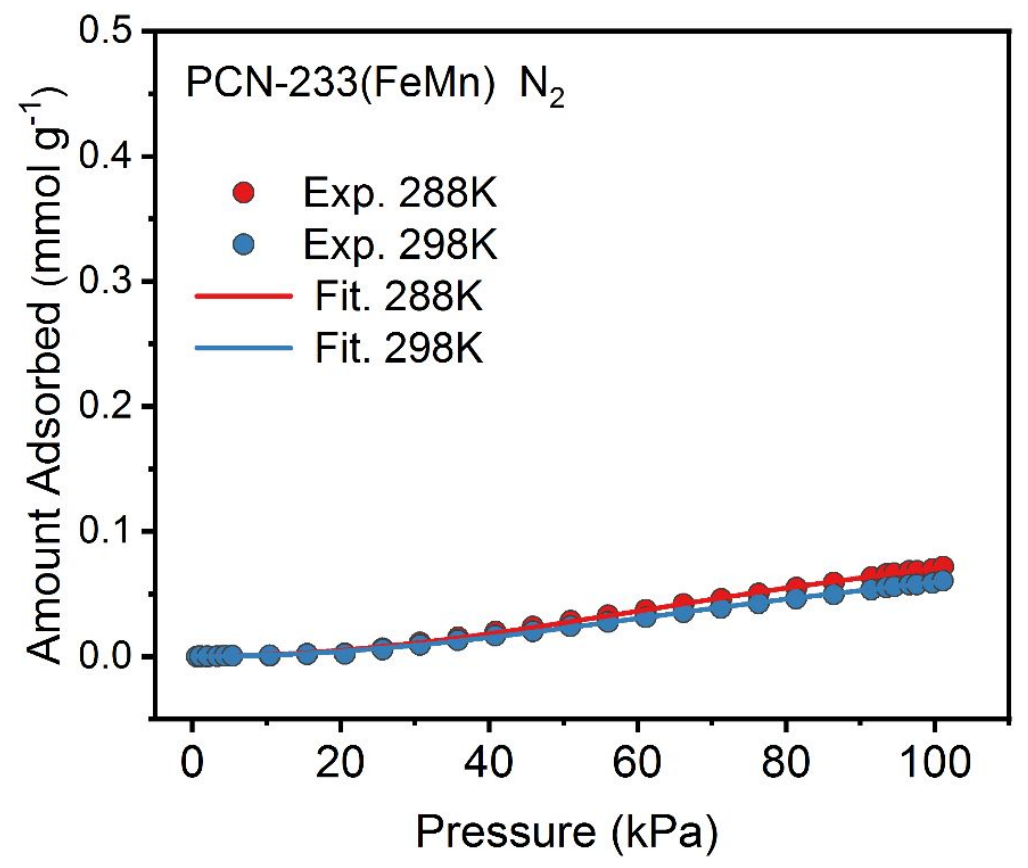

Figure S33 Experimental and DSLF fitting adsorption isotherms of $\mathrm{N}_{2}$ for PCN$233(\mathrm{FeMn})$ at $288 \mathrm{~K}$ and $298 \mathrm{~K}$.

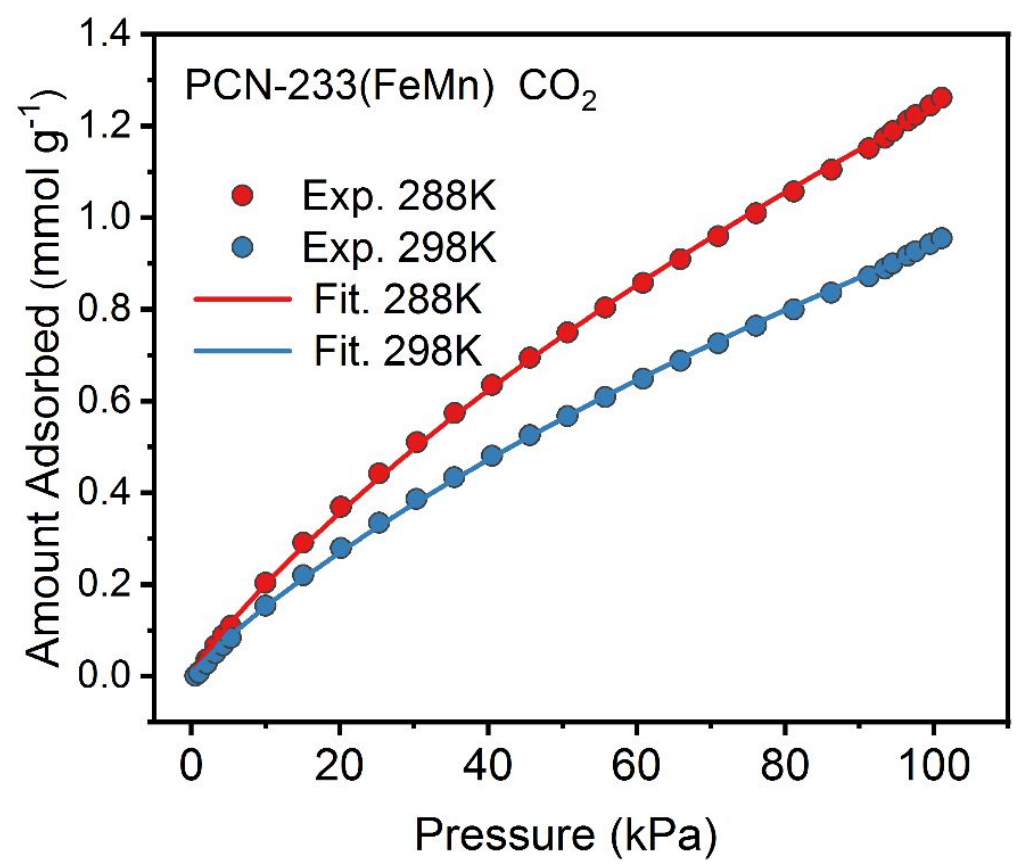

Figure S34 Experimental and DSLF fitting adsorption isotherms of $\mathrm{CO}_{2}$ for PCN$233(\mathrm{FeMn})$ at $288 \mathrm{~K}$ and $298 \mathrm{~K}$. 


\subsection{Calculation of heat of adsorption}

Experimental isosteric heat of adsorption $\left(\mathrm{Q}_{\mathrm{st}}\right)$ for different gas molecules on MOFs were calculated using the Clausius-Clapeyron equation with different temperatures: ${ }^{16}$

$$
\left(\frac{Q \text { st }}{R}\right)=\left(\frac{\partial \ln P}{\partial\left(\frac{1}{T}\right)}\right)_{\theta}
$$

Where $T$ is the temperature, $P$ is the pressure, $R$ is the ideal gas constant and $\theta$ indicates a certain and constant coverage status.

Table S6 Isosteric heat of adsorption for $\mathrm{C}_{2} \mathrm{H}_{6}, \mathrm{C}_{2} \mathrm{H}_{4}, \mathrm{CO}_{2}$ and $\mathrm{CH}_{4}$ on the MOFs at the initial loadings

\begin{tabular}{ccccc}
\hline & $\mathrm{C}_{2} \mathrm{H}_{6}$ & $\mathrm{CH}_{4}$ & $\mathrm{CO}_{2}$ & $\mathrm{~N}_{2}$ \\
\hline MIL-160(Al) & 32.00 & 20.36 & 31.87 & 16.32 \\
PCN-233(FeNi) & 23.70 & 18.23 & 20.80 & 11.60 \\
PCN-233(FeCo) & 20.87 & 15.22 & 18.25 & 10.72 \\
PCN-233(FeMn) & 22.51 & 16.40 & 18.41 & 12.66 \\
\hline
\end{tabular}

Unit: $\mathrm{kJ} / \mathrm{mol}$ 


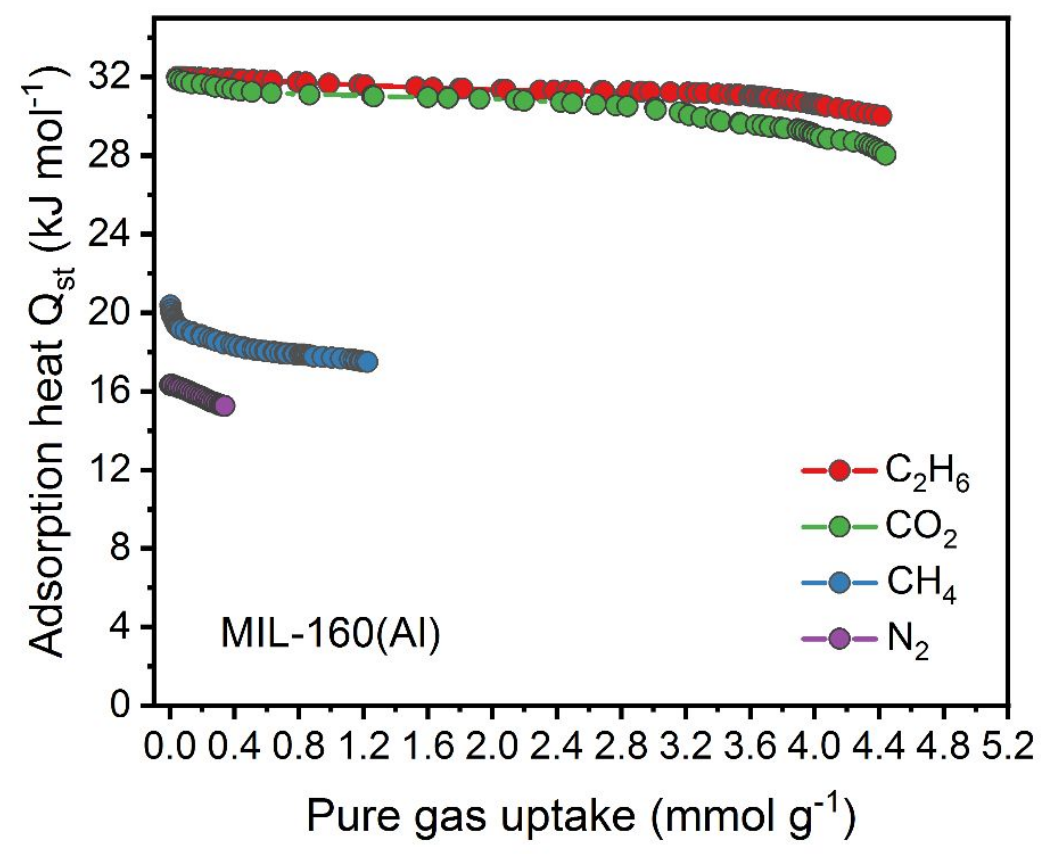

Figure S35 Isosteric heat of adsorption for $\mathrm{C}_{2} \mathrm{H}_{6}, \mathrm{CH}_{4}, \mathrm{~N}_{2}$ and $\mathrm{CO}_{2}$ on MIL-160(Al).

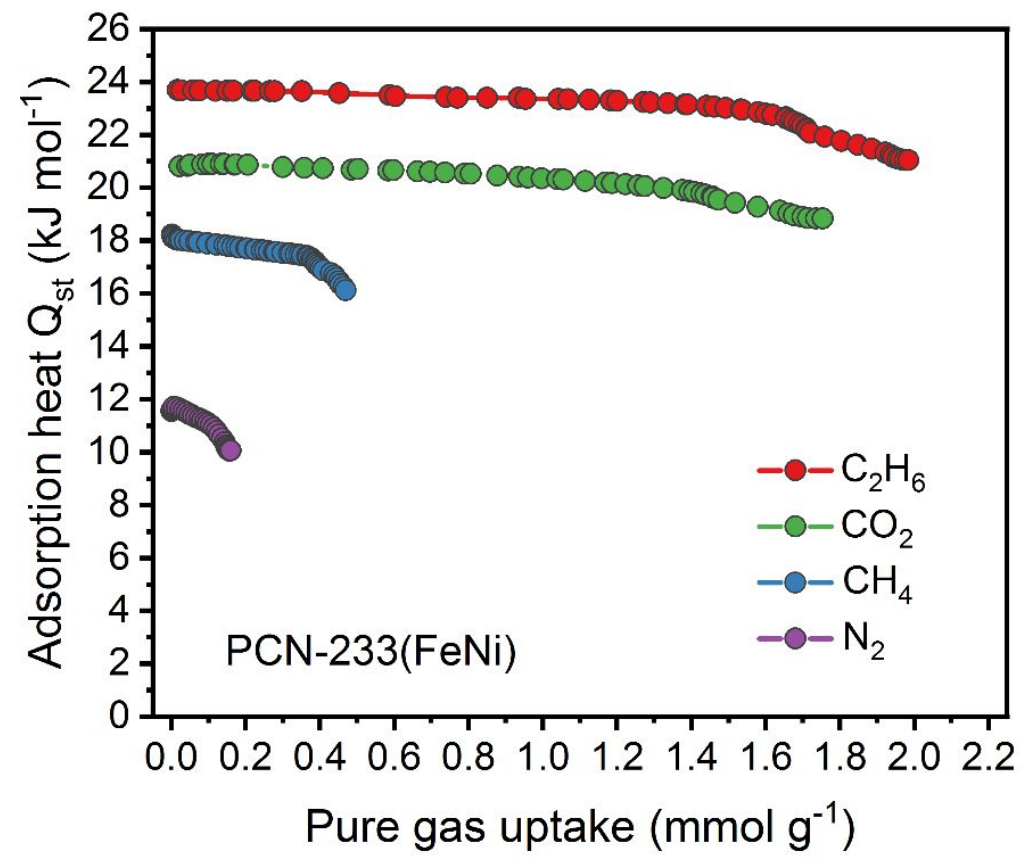

Figure S36 Isosteric heat of adsorption for $\mathrm{C}_{2} \mathrm{H}_{6}, \mathrm{CH}_{4}, \mathrm{~N}_{2}$ and $\mathrm{CO}_{2}$ on $\mathrm{PCN}-233(\mathrm{FeNi})$. 


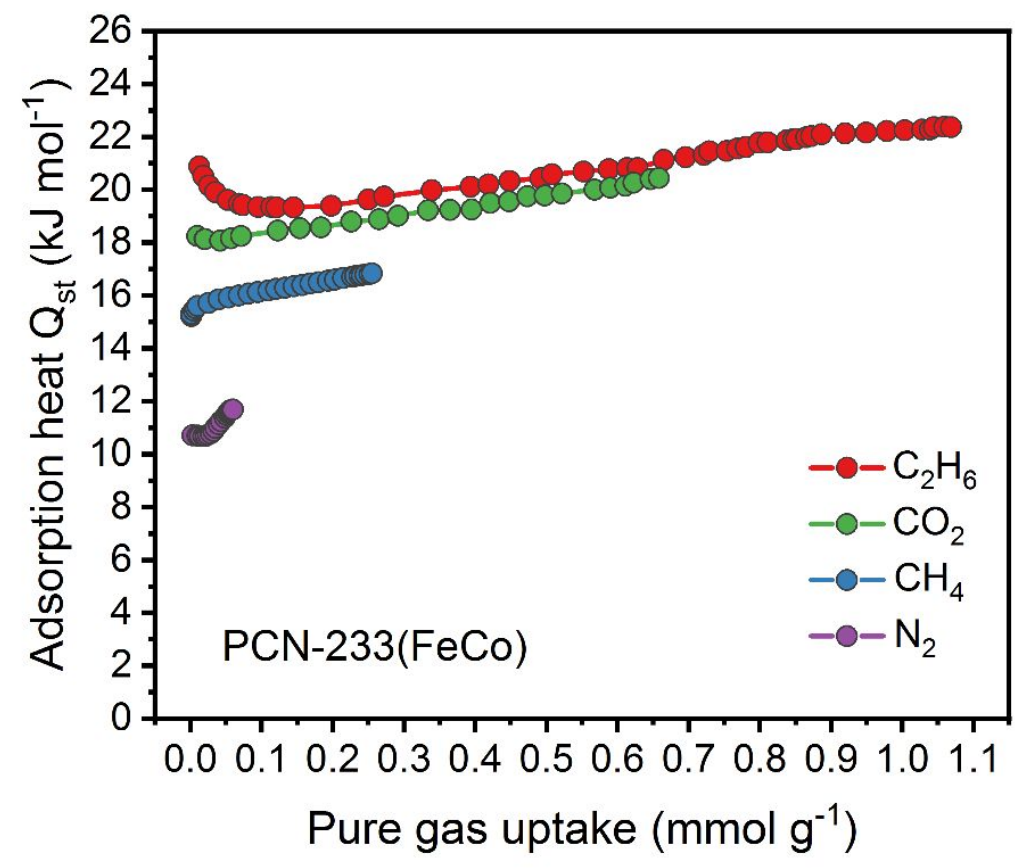

Figure S37 Isosteric heat of adsorption for $\mathrm{C}_{2} \mathrm{H}_{6}, \mathrm{CH}_{4}, \mathrm{~N}_{2}$ and $\mathrm{CO}_{2}$ on $\mathrm{PCN}-233(\mathrm{FeCo})$.

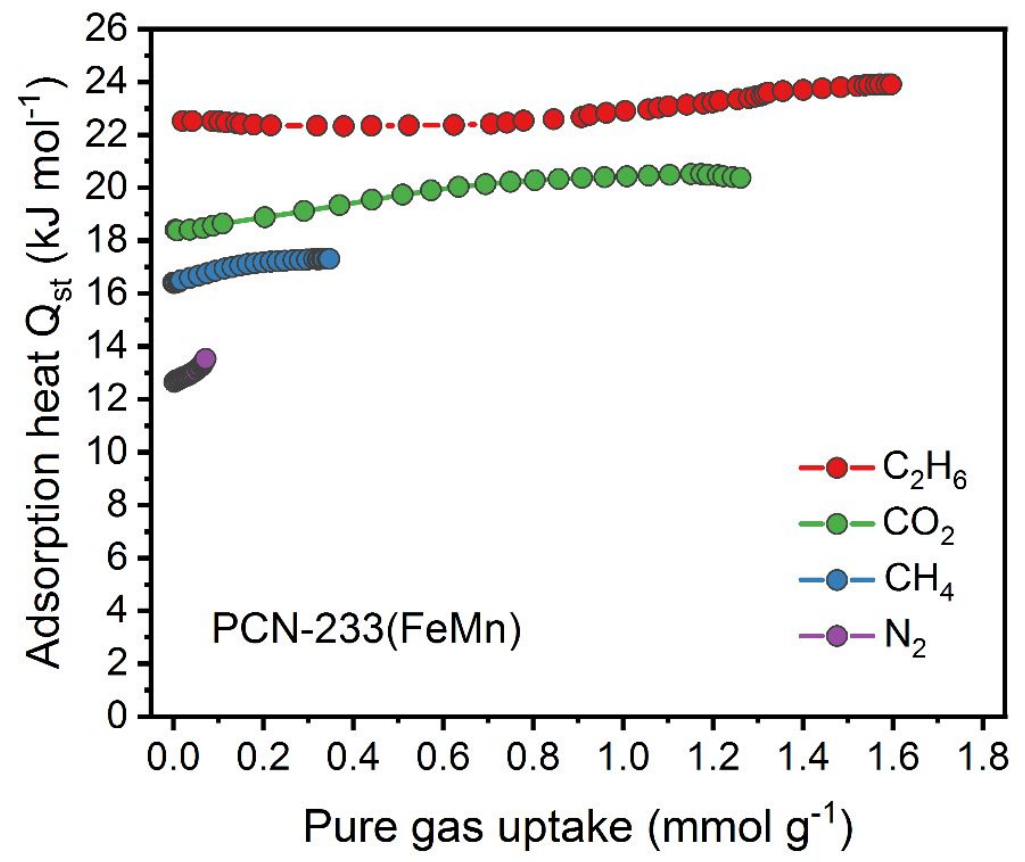

Figure S38 Isosteric heat of adsorption for $\mathrm{C}_{2} \mathrm{H}_{6}, \mathrm{CH}_{4}, \mathrm{~N}_{2}$ and $\mathrm{CO}_{2}$ on $\mathrm{PCN}-233(\mathrm{FeMn})$. 


\subsection{Calculation of adsorption selectivity}

The ideal adsorbed solution theory (IAST) was widely used to predict the adsorption of gas mixture on MOFs simply on the basis of the pure component adsorption isotherms. ${ }^{17}$

The IAST selectivities were calculated as:

$$
S_{i, j}=\frac{(n / y)_{i}}{(n / y)_{j}}
$$

Where $i$ and $j$ represent the two different gases, $n$ is the mole amount of gas molecules in the adsorbed phase, $y$ is the proposed mole fraction of the corresponding gas in the mixture.

Table S7 $\mathrm{C}_{2} \mathrm{H}_{6} / \mathrm{CH}_{4}(5 / 95, \mathrm{v} / \mathrm{v})$ IAST selectivity and DSLF adsorption fitting parameters of renewable MOFs at $298 \mathrm{~K}$

\begin{tabular}{|c|c|c|c|c|c|c|c|c|}
\hline & \multicolumn{2}{|c|}{ MIL-160(Al) } & \multicolumn{2}{|c|}{ PCN-233(FeNi) } & \multicolumn{2}{|c|}{ PCN-233(FeCo) } & \multicolumn{2}{|c|}{ PCN-233(FeMn) } \\
\hline IAST & \multirow{2}{*}{\multicolumn{2}{|c|}{$29.90 / 14.74$}} & & & & & & \\
\hline Selectivity & & & \multicolumn{2}{|c|}{$18.17 / 12.15$} & \multicolumn{2}{|c|}{$14.89 / 10.28$} & \multicolumn{2}{|c|}{$19.01 / 12.14$} \\
\hline Gas & $\mathrm{C}_{2} \mathrm{H}_{6}$ & $\mathrm{CH}_{4}$ & $\mathrm{C}_{2} \mathrm{H}_{6}$ & $\mathrm{CH}_{4}$ & $\mathrm{C}_{2} \mathrm{H}_{6}$ & $\mathrm{CH}_{4}$ & $\mathrm{C}_{2} \mathrm{H}_{6}$ & $\mathrm{CH}_{4}$ \\
\hline$q_{1}$ & 5.5298 & 2.9988 & 2.7757 & 1.6159 & 1.5479 & 1.0845 & 2.3195 & 1.8964 \\
\hline$b_{1}$ & 0.0142 & 0.0019 & 0.0235 & 0.0027 & 0.0158 & 0.0011 & 0.0191 & 0.0011 \\
\hline$c_{1}$ & 1.1433 & 1.1492 & 0.9017 & 1.0091 & 0.9494 & 1.0334 & 0.9071 & 1.0013 \\
\hline $\begin{array}{l}q_{2} \\
\text { (dual site) }\end{array}$ & 0.6709 & 0.8017 & 0.8965 & 0.8067 & 0.7930 & 0.9485 & 0.8640 & 1.2867 \\
\hline $\begin{array}{l}b_{2} \\
\text { (dual site) }\end{array}$ & 0.0010 & 0.0009 & 0.0009 & 0.0008 & 0.0008 & 0.0008 & 0.0010 & 0.0009 \\
\hline $\begin{array}{l}c_{2} \\
\text { (dual site) }\end{array}$ & 0.5018 & 0.9401 & 0.9051 & 0.9149 & 0.6439 & 0.9776 & 0.8928 & 0.9832 \\
\hline $\mathrm{R}^{2}$ & 0.9999 & 0.9698 & 0.9999 & 0.9810 & 0.9999 & 0.9815 & 0.9999 & 0.98074 \\
\hline
\end{tabular}




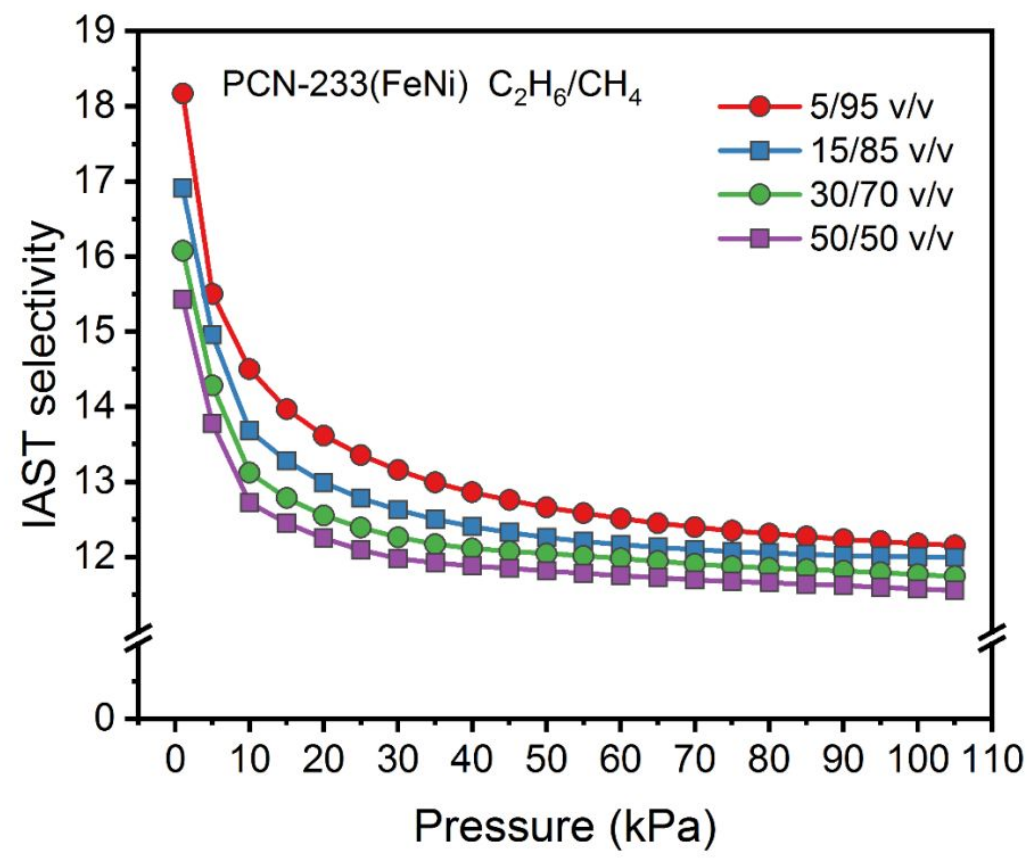

Figure S39 The IAST selectivities of $\mathrm{C}_{2} \mathrm{H}_{6} / \mathrm{CH}_{4}$ mixtures with gas compositions of $5: 95,15: 85,30: 70$, and 50:50 v/v at $298 \mathrm{~K}$ for PCN-233(FeNi).

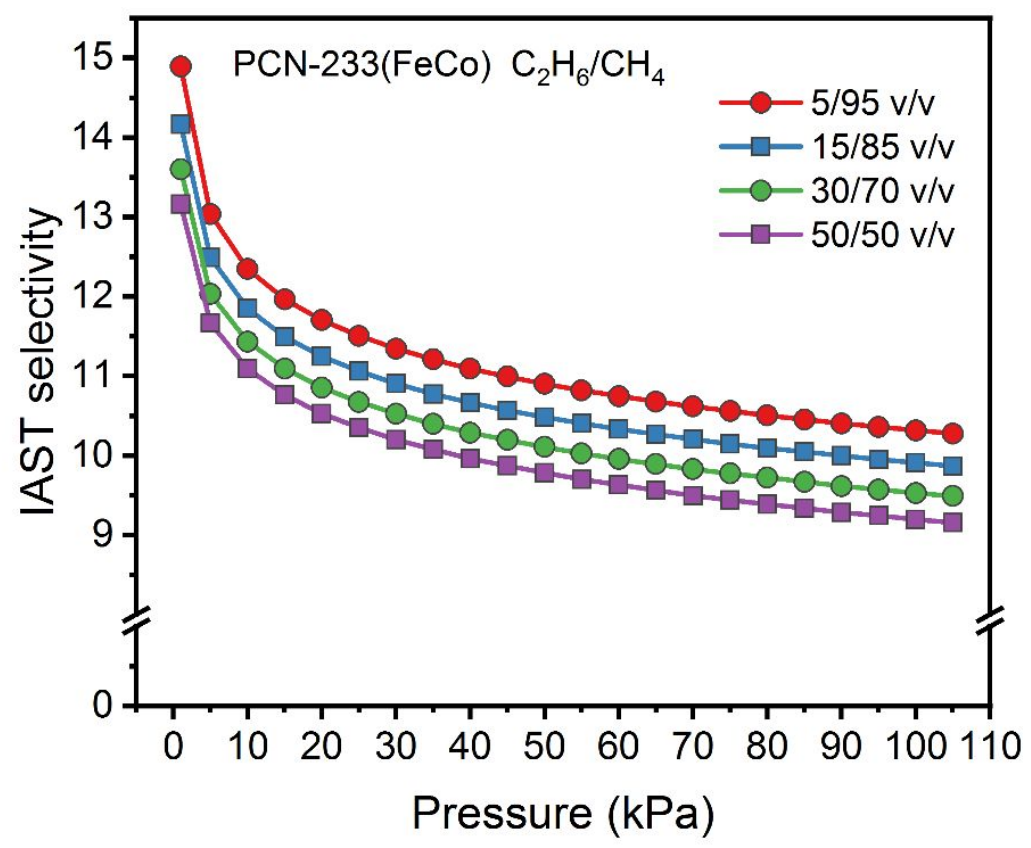

Figure S40 The IAST selectivities of $\mathrm{C}_{2} \mathrm{H}_{6} / \mathrm{CH}_{4}$ mixtures with gas compositions of $5: 95,15: 85,30: 70$, and 50:50 v/v at $298 \mathrm{~K}$ for PCN-233(FeCo). 


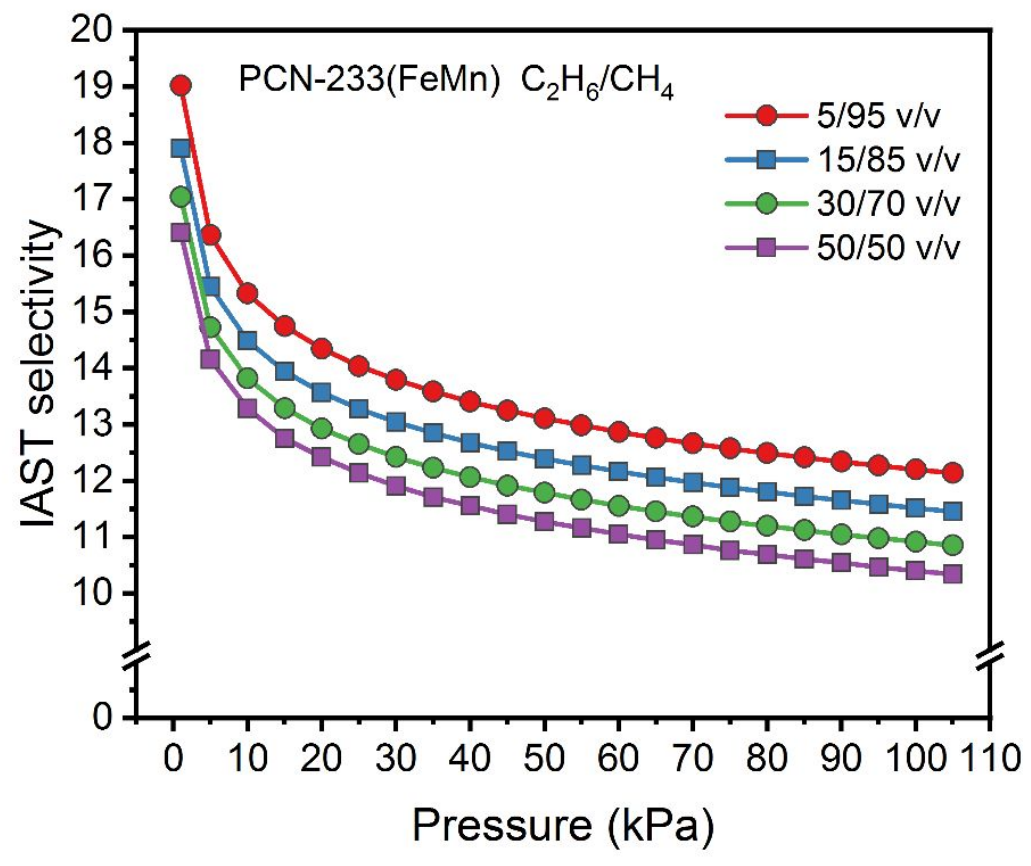

Figure S41 The IAST selectivities of $\mathrm{C}_{2} \mathrm{H}_{6} / \mathrm{CH}_{4}$ mixtures with gas compositions of $5: 95,15: 85,30: 70$, and 50:50 v/v at $298 \mathrm{~K}$ for PCN-233(FeMn). 


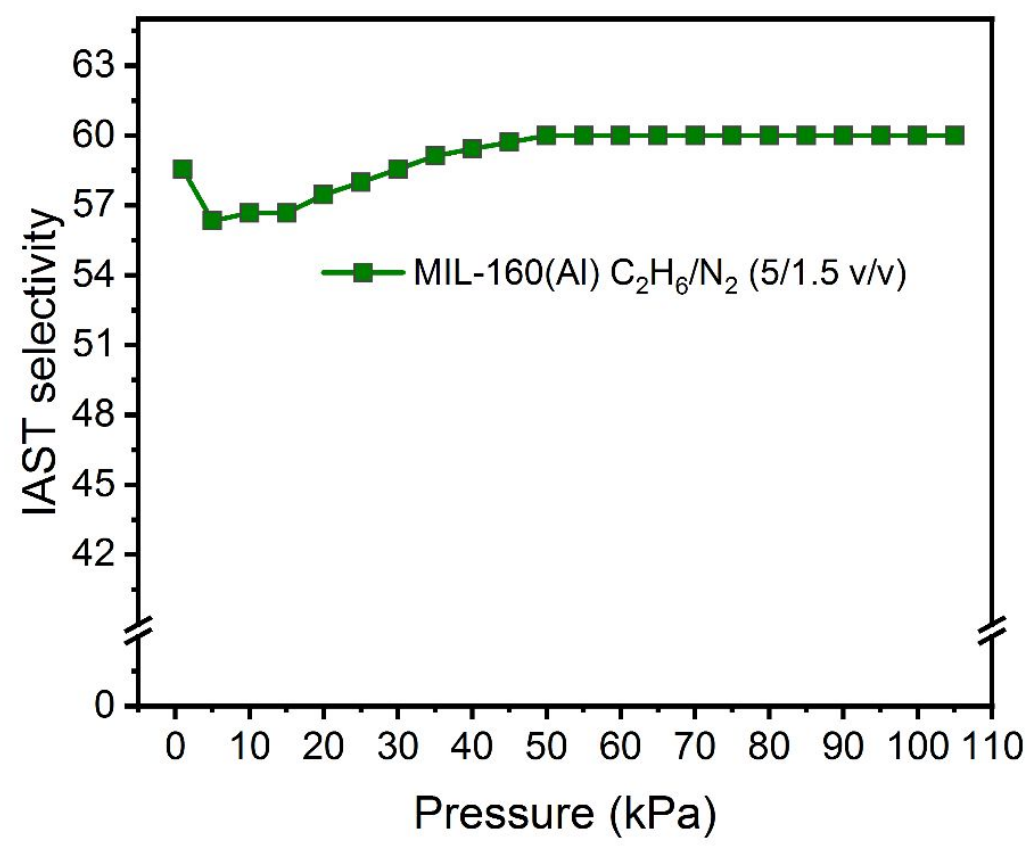

Figure S42 IAST selectivity of $\mathrm{C}_{2} \mathrm{H}_{6} / \mathrm{N}_{2}(5 / 1.5$, v/v) for MIL-160(Al) at $298 \mathrm{~K}$.

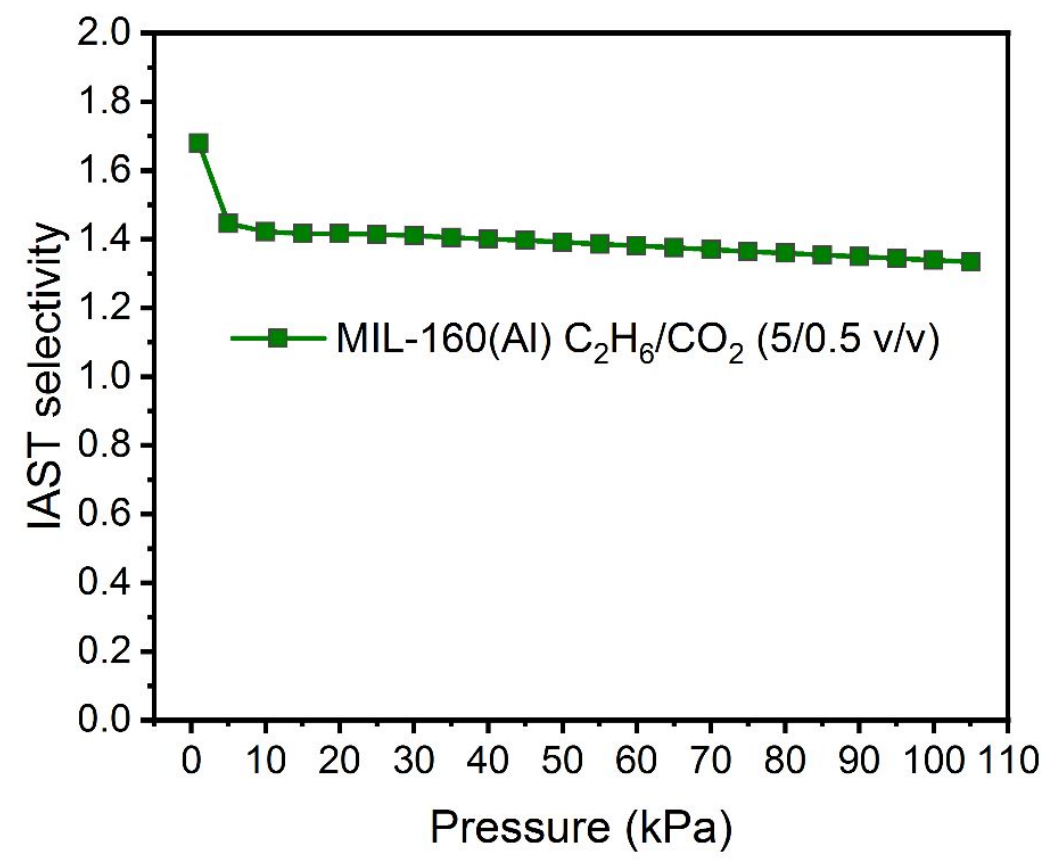

Figure S43 IAST selectivity of $\mathrm{C}_{2} \mathrm{H}_{6} / \mathrm{CO}_{2}(5 / 0.5, \mathrm{v} / \mathrm{v})$ for MIL-160(Al) at $298 \mathrm{~K}$. 


\subsection{Calculation of dynamic selectivity}

The real selectivity of $\mathrm{CH}_{4} / \mathrm{C}_{2} \mathrm{H}_{6}$ on MIL-160(Al) could be computed via the dynamic adsorption process, i.e., the breakthrough experiments. At $298 \mathrm{~K}$ and 1 bar, the selectivity was calculated via the formulas of (3-3) and (3-4) ${ }^{18}$ :

$$
q_{i}=\frac{\left(F_{0, i} C_{0, i} t_{1}-\int_{0}^{t_{1}} F_{i} C(t) d t\right)-V_{d}}{m}
$$

where $F_{i}$ is the flow rate of gas component $i$ in the mixture gas; $m$ is the weight of adsorbent; $C(t)$ is the concentration of component $i$ in the gas phase at instantaneous $t ; t_{1}$ is the stable moment of the breakthrough curve of component $i$ leaving the column, and $V_{d}$ is the dead volume of the set-up. 


\section{Water microcalorimetric and adsorption measurement}

Water microcalorimetric measurement for the renewable MOFs were performed on a BT2.15 heat-flux calorimeter, which was connected to a gas handling and a volumetric system employing MKS Baratron Capacitance Manometers for precise determination of pressure. The microcalorimetric system was operated under an ultimate dynamic vacuum of $10^{-7}$ Torr. Fresh samples were first heated at $433 \mathrm{~K}$ under vacuum overnight in a special glass cell, and then the cell was placed into the high vacuum system and stabilized for $12 \mathrm{~h}$. The microcalorimetric data was collected through sequentially introducing small doses ( 0.2 torr) of water vapor into the system under $313 \mathrm{~K}$, with the relative pressure of injection increased gradually ( $\sim 10$ torr). Water adsorption isotherms could then be obtained, and the differential adsorption heat versus adsorbate coverage was tabulated.

Table S8 Differential adsorption heat of $\mathrm{H}_{2} \mathrm{O}$ on MOFs

\begin{tabular}{cccccc}
\hline \multirow{2}{*}{ Entry } & \multirow{2}{*}{ Sorbent } & \multicolumn{2}{c}{$\mathrm{H}_{2} \mathrm{O}$ initial loading } & \multicolumn{2}{c}{$\mathrm{H}_{2} \mathrm{O}$ final loading } \\
\cline { 3 - 6 } & & Heat & Coverage & Heat & Coverage \\
& & $(\mathrm{kJ} / \mathrm{mol})$ & $(\mu \mathrm{mol} / \mathrm{g})$ & $(\mathrm{kJ} / \mathrm{mol})$ & $(\mu \mathrm{mol} / \mathrm{g})$ \\
\hline 1 & MIL-160(Al) & 51.92575 & 6.44573 & 56.17561 & 742.12056 \\
2 & PCN-233(FeNi) & 52.37755 & 0.92674 & 67.79103 & 451.89565 \\
3 & PCN-233(FeCo) & 47.96315 & 1.85657 & 77.19175 & 417.78232 \\
4 & PCN-233(FeMn) & 50.49702 & 4.89480 & 62.96208 & 732.59250 \\
\hline
\end{tabular}




\section{Density functional theory calculations}

The static binding energy, sorption sites and surface electrostatic potential of frameworks were calculated using the combination of first-principle density functional theory calculations (DFT) using the Vienna Ab-initio Simulation Package (VASP) package. ${ }^{19}$ The generalized gradient approximation (GGA) with the Perdew-BurkeErnzerhof (PBE) functional were used to describe the electronic exchange and correlation effects. Uniform G-centered k-points meshes with a resolution of $2 \pi^{*} 0.04$ $\AA^{-1}$ and Methfessel-Paxton electronic smearing were adopted for the integration in the Brillouin zone for geometric optimization. ${ }^{20-22}$ The simulation run with a cutoff energy of $600 \mathrm{eV}$ throughout the computations. These settings ensure convergence of the total energies to within $1 \mathrm{meV}$ per atom. Structure relaxation proceeded until all forces on atoms were less than $1 \mathrm{meV} \AA^{-1}$ and the total stress tensor was within $0.01 \mathrm{GPa}$ of the target value.

The calculations of electrostatic potential on the ground-state potential energy surfaces of MOFs have been performed by DFT approach with the 6-31G basis set. ${ }^{23}$ The Becke's three-parameter hybrid exchange functional and the Lee-Yang-Parr correlation functional (B3LYP) implemented in the GAUSSIAN 03 package have been used in the DFT calculation. ${ }^{24-25}$

Static binding energies $(\Delta \mathrm{E})$ at $0 \mathrm{~K}$ were calculated using the following expression, where $E_{\mathrm{MOF}+\text { gas }}, E_{\mathrm{MOF}}$ and $E_{\text {gas }}$ refer to the total energies of the MOF+gas complex, the $\mathrm{MOF}$, and gas molecule, respectively:

$$
\Delta E=E_{\mathrm{MOF}+\text { gas }}-E_{\mathrm{MOF}}-E_{\mathrm{gas}}
$$

Table S9 Static binding energies of $\mathrm{CH}_{4}$ and $\mathrm{C}_{2} \mathrm{H}_{6}$ on MIL-160(Al)

\begin{tabular}{l|c|ccccc}
\hline Sorbents & Molecule & $\mathrm{E}(\mathrm{MOF}+\mathrm{gas})$ & $\mathrm{E}(\mathrm{MOF})$ & $\mathrm{E}(\mathrm{gas})$ & $\Delta \mathrm{E}(\mathrm{eV})$ & $\Delta \mathrm{E}(\mathrm{kJ} / \mathrm{mol})$ \\
\hline \multirow{2}{*}{ MIL-160(Al) } & $\mathrm{CH}_{4}$ & -1857.56 & -1833.29 & -24.04 & -0.23 & $-22.17^{26}$ \\
& $\mathrm{C}_{2} \mathrm{H}_{6}$ & -1874.13 & -1833.29 & -40.50 & -0.34 & -32.27 \\
\hline
\end{tabular}

Table S10 Static binding energies of water on MIL-160(Al) and PCN-233(FeNi)

\begin{tabular}{l|ccccc}
\hline Sorbents & $\mathrm{E}\left(\mathrm{MOF}+\mathrm{H}_{2} \mathrm{O}\right)$ & $\mathrm{E}(\mathrm{MOF})$ & $\mathrm{E}\left(\mathrm{H}_{2} \mathrm{O}\right)$ & $\Delta \mathrm{E}(\mathrm{eV})$ & $\Delta \mathrm{E}(\mathrm{kJ} / \mathrm{mol})$ \\
\hline MIL-160(Al) & -1848.08 & -1833.29 & -14.23 & -0.56 & $-54.00^{27}$ \\
$\mathrm{PCN}-233(\mathrm{FeNi})$ & -700.29 & -685.44 & -14.23 & -0.62 & -59.71 \\
\hline
\end{tabular}




\section{Summary of $\mathrm{C}_{2} \mathrm{H}_{6}$ adsorption and separation performance of MOFs}

Table S11 $\mathrm{C}_{2} \mathrm{H}_{6}$ capacity, IAST selectivity and volumetric adsorption ratio of $\mathrm{C}_{2} \mathrm{H}_{6} / \mathrm{CH}_{4}$ at $298 \mathrm{~K}$ and 1 bar for various state-of-the-art MOFs

\begin{tabular}{|c|c|c|c|c|}
\hline Sorbents & $\begin{array}{c}\mathrm{C}_{2} \mathrm{H}_{6} \text { capacity } \\
\mathrm{mmolg}^{-1}\end{array}$ & $\begin{array}{c}\mathrm{C}_{2} \mathrm{H}_{6} / \mathrm{CH}_{4} \\
\text { IAST selectivity }\end{array}$ & $\begin{array}{l}\mathrm{C}_{2} \mathrm{H}_{6} / \mathrm{CH}_{4} \\
\mathrm{v} / \mathrm{v} 1 \mathrm{bar} \\
\end{array}$ & Reference \\
\hline IRMOF-8 & 6.00 & I & I & 28 \\
\hline $\mathrm{Fe}_{2}(\mathrm{dobdc})$ & 5.00 & 20.00 & 6.5 & 29 \\
\hline $\mathrm{Ni}(\mathrm{bdc})($ ted) 0.5 & 4.80 & / & 1 & 30 \\
\hline UTSA-34 & 4.12 & $19.50^{\mathrm{d}^{*}}$ & 5.34 & 31 \\
\hline MIL-160(Al) & 4.05 & $29.90^{\mathrm{a}}$ & 4.60 & This work \\
\hline In-soc-MOF-1 & 4.04 & l & l & 32 \\
\hline MIL-142A & 3.82 & $13.7^{\mathrm{d}}$ & 7.07 & 33 \\
\hline ZnP-CTFs & 3.04 & 23.20 & 5.60 & 34 \\
\hline UiO-67 & 3.00 & $7.50^{\mathrm{d}}$ & 6.66 & 35 \\
\hline UTSA-33 & 2.77 & $16.00^{\mathrm{d}^{*}}$ & 3.53 & 36 \\
\hline UTSA-35 & 2.43 & $14.00^{\mathrm{d}^{*}}$ & 4.50 & 37 \\
\hline RT-MIL-100(Fe) & 2.22 & $6.00^{\mathrm{c}}$ & 6.20 & 38 \\
\hline $\mathrm{RT}-\mathrm{Cu}(\mathrm{Qc})_{2}$ & 2.04 & $20.9^{b}$ & 22.67 & 39 \\
\hline PAF-40-Mn & 2.01 & 32.00 & 4.50 & 40 \\
\hline PAF-40 & 1.92 & 18.00 & 3.30 & 40 \\
\hline MAF-49 & 1.73 & I & 1.90 & 41 \\
\hline PCN-233(FeNi) & 1.72 & $18.17^{\mathrm{a}}$ & 4.30 & This work \\
\hline PAF-40-Fe & 1.65 & 14.00 & 3.00 & 40 \\
\hline PCN-233(FeMn) & 1.43 & $19.01^{\mathrm{a}}$ & 4.90 & This work \\
\hline PCN-233(FeCo) & 0.88 & $14.89^{\mathrm{a}}$ & 4.30 & This work \\
\hline
\end{tabular}

IAST selectivity for $\mathrm{C}_{2} \mathrm{H}_{6} / \mathrm{CH}_{4}:{ }^{\text {a }} 5 / 95 \mathrm{v} / \mathrm{v},{ }^{\mathrm{b}} 10 / 90,{ }^{\mathrm{c}} 10 / 85,{ }^{\mathrm{d}} 50 / 50$.

$* 296 \mathrm{~K}$. 


\section{References and notes}

1. Takagaki, A.; Ohara, M.; Nishimura, S.; Ebitani, K., A one-pot reaction for biorefinery: combination of solid acid and base catalysts for direct production of 5-hydroxymethylfurfural from saccharides. Chem. Commun. (Camb.) 2009, 45 (41), 6276-6278. DOI: 10.1039/b914087e.

2. Ohara, M.; Takagaki, A.; Nishimura, S.; Ebitani, K., Syntheses of 5-hydroxymethylfurfural and levoglucosan by selective dehydration of glucose using solid acid and base catalysts. Appl. Catal. AGen.l 2010, 383 (1-2), 149-155. DOI: 10.1016/j.apcata.2010.05.040.

3. Zhang, L.; Luo, X. L.; Li, Y. B., A new approach for the aerobic oxidation of 5hydroxymethylfurfural to 2,5-furandicarboxylic acid without using transition metal catalysts. J. Energy Chem. 2018, 27 (1), 243-249. DOI: 10.1016/j.jechem.2017.04.020

4. Serre, C.; Millange, F.; Surble, S.; Ferey, G., A route to the synthesis of trivalent transition-metal porous carboxylates with trimeric secondary building units. Angew. Chem. Int. Ed. Engl. 2004, 43 (46), 6285-6289. DOI: 10.1002/anie.200454250.

5. Feng, D.; Wang, K.; Wei, Z.; Chen, Y. P.; Simon, C. M.; Arvapally, R. K.; Martin, R. L.; Bosch, M.; Liu, T. F.; Fordham, S.; Yuan, D.; Omary, M. A.; Haranczyk, M.; Smit, B.; Zhou, H. C., Kinetically tuned dimensional augmentation as a versatile synthetic route towards robust metal-organic frameworks. Nat. Commun. 2014, 5, 5723. DOI: 10.1038/ncomms6723.

6. Chen, Y.; Qiao, Z.; Huang, J.; Wu, H.; Xiao, J.; Xia, Q.; Xi, H.; Hu, J.; Zhou, J.; Li, Z., Unusual Moisture-Enhanced CO2 Capture within Microporous PCN-250 Frameworks. ACS Appl. Mater. Interfaces 2018, 10 (44), 38638-38647. DOI: 10.1021/acsami.8b14400.

7. Wahiduzzaman, M.; Lenzen, D.; Maurin, G.; Stock, N.; Wharmby, M. T., Rietveld Refinement of MIL-160 and Its Structural Flexibility Upon $\mathrm{H} 2 \mathrm{O}$ and N2 Adsorption. Eur. J. Inorg. Chem. 2018, 2018 (32), 3626-3632. DOI: 10.1002/ejic.201800323.

8. Jiang, Y.; Woortman, A. J. J.; van Ekenstein, G. O. R. A.; Loos, K., A biocatalytic approach towards sustainable furanic-aliphatic polyesters. Polymer Chem. 2015, 6 (29), 5198-5211. DOI: 10.1039/c5py00629e.

9. Silva, M. P.; Ribeiro, A. M.; Silva, C. G.; Nogueira, I. B. R.; Cho, K.-H.; Lee, U. H.; Faria, J. L.; Loureiro, J. L.; Chang, J.-S.; Rodrigues, A. E.; Ferreira, A., MIL-160(Al) MOF's potential in adsorptive water harvesting. Adsorption 2021, 27 (2), 213-226. DOI: 10.1007/s10450-020-00286-5.

10. Gomez-Gualdron, D. A.; Moghadam, P. Z.; Hupp, J. T.; Farha, O. K.; Snurr, R. Q., Application of Consistency Criteria To Calculate BET Areas of Micro- And Mesoporous Metal-Organic Frameworks. J. Am. Chem. Soc. 2016, 138 (1), 215-224. DOI: 10.1021/jacs.5b10266.

11. Galarneau, A.; Villemot, F.; Rodriguez, J.; Fajula, F.; Coasne, B., Validity of the t-plot method to assess microporosity in hierarchical micro/mesoporous materials. Langmuir 2014, 30 (44), 13266-13274. DOI: $10.1021 / 1 a 5026679$. 
12. Mason, J. A.; Veenstra, M.; Long, J. R., Evaluating metal-organic frameworks for natural gas storage. Chem. Sci. 2014, 5 (1), 32-51. DOI: 10.1039/c3sc52633j.

13. Yoon, J. W.; Chang, H.; Lee, S.-J.; Hwang, Y. K.; Hong, D.-Y.; Lee, S.-K.; Lee, J. S.; Jang, S.; Yoon, T.-U.; Kwac, K.; Jung, Y.; Pillai, R. S.; Faucher, F.; Vimont, A.; Daturi, M.; Ferey, G.; Serre, C.; Maurin, G.; Bae, Y.-S.; Chang, J.-S., Selective nitrogen capture by porous hybrid materials containing accessible transition metal ion sites. Nat. Mater. 2017, 16 (5), 526-531. DOI: 10.1038/nmat4825.

14. Sips, R., On the Structure of a Catalyst Surface. J. Chem. Phys. 1948, 16 (5), 490-495. DOI: $10.1063 / 1.1746922$.

15. Rivera-Ramos, M. E.; Hernández-Maldonado, A. J., Adsorption of N2 and CH4 by Ion-Exchanged Silicoaluminophosphate Nanoporous Sorbents: Interaction with Monovalent, Divalent, and Trivalent Cations. Ind. Eng. Chem. Res. 2007, 46 (14), 4991-5002. DOI: 10.1021/ie061016m.

16. Çengel, Y. A. B., Michael A., Thermodynamics - An Engineering Approach. McGraw-Hill: Boston, MA., 1998.

17. Li, L. Y.; Yang, L. F.; Wang, J. W.; Zhang, Z. G.; Yang, Q. W.; Yang, Y. W.; Ren, Q. L.; Bao, Z. B., Highly efficient separation of methane from nitrogen on a squarate-based metal-organic framework. AIChE J. 2018, 64 (10), 3681-3689. DOI: 10.1002/aic.16335.

18. Peralta, D.; Chaplais, G.; Simon-Masseron, A.; Barthelet, K.; Chizallet, C.; Quoineaud, A. A.; Pirngruber, G. D., Comparison of the behavior of metal-organic frameworks and zeolites for hydrocarbon separations. J. Am. Chem. Soc. 2012, 134 (19), 8115-8126. DOI: 10.1021/ja211864w.

19. Kresse, G.; Furthmuller, J., Efficiency of ab-initio total energy calculations for metals and semiconductors using a plane-wave basis set. Computational Mater. Sci. 1996, 6 (1), 15-50. DOI: 10.1016/0927-0256(96)00008-0.

20. Perdew, J. P.; Burke, K.; Ernzerhof, M., Generalized Gradient Approximation Made Simple. Phys. Rev. Lett. 1996, 77 (18), 3865-3868. DOI: 10.1103/PhysRevLett.77.3865.

21. Kresse, G.; Joubert, D., From ultrasoft pseudopotentials to the projector augmented-wave method. Phys. Rev. B 1999, 59 (3), 1758-1775. DOI: 10.1103/PhysRevB.59.1758.

22. Blochl, P. E., Projector augmented-wave method. Phys. Rev. B: Condens Matter 1994, 50 (24), 17953-17979. DOI: 10.1103/physrevb.50.17953.

23. Rassolov, V. A.; Ratner, M. A.; Pople, J. A.; Redfern, P. C.; Curtiss, L. A., 6-31G*basis set for third-row atoms. J. Comput. Chem. 2001, 22 (9), 976-984. DOI: 10.1002/jcc.1058.

24. Gaussian 03, Revision C.02, Gaussian, Inc.: Wallingford CT, 2004.

25. Becke, A. D., Density - functional thermochemistry. III. The role of exact exchange. The Journal of Chem. Phys. 1993, 98 (7), 5648-5652. DOI: 10.1063/1.464913.

26. Borges, D. D.; Normand, P.; Permiakova, A.; Babarao, R.; Heymans, N.; Galvao, D. S.; Serre, C.; De Weireld, G.; Maurin, G., Gas Adsorption and Separation by the Al-Based Metal-Organic Framework MIL-160. J. Phys. Chem. C 2017, 121 (48), 26822-26832. DOI: 10.1021/acs.jpcc.7b08856. 
27. Cadiau, A.; Lee, J. S.; Damasceno Borges, D.; Fabry, P.; Devic, T.; Wharmby, M. T.; Martineau, C.; Foucher, D.; Taulelle, F.; Jun, C. H.; Hwang, Y. K.; Stock, N.; De Lange, M. F.; Kapteijn, F.; Gascon, J.; Maurin, G.; Chang, J. S.; Serre, C., Design of hydrophilic metal organic framework water adsorbents for heat reallocation. Adv. Mater. 2015, 27 (32), 4775-4780. DOI: 10.1002/adma.201502418.

28. Pires, J.; Pinto, M. L.; Saini, V. K., Ethane selective IRMOF-8 and its significance in ethaneethylene separation by adsorption. ACS Appl. Mater. Interfaces 2014, 6 (15), 12093-12099. DOI: $10.1021 / \mathrm{am} 502686 \mathrm{~g}$.

29. Bloch, E. D.; Queen, W. L.; Krishna, R.; Zadrozny, J. M.; Brown, C. M.; Long, J. R., Hydrocarbon separations in a metal-organic framework with open iron(II) coordination sites. Science 2012, 335 (6076), 1606-1610. DOI: $10.1126 /$ science. 1217544.

30. Xiang, H.; Ameen, A.; Gorgojo, P.; Siperstein, F. R.; Holmes, S. M.; Fan, X., Selective adsorption of ethane over ethylene on $\mathrm{M}(\mathrm{bdc})(\mathrm{ted}) 0.5(\mathrm{M}=\mathrm{Co}, \mathrm{Cu}, \mathrm{Ni}, \mathrm{Zn}$ ) metal-organic frameworks (MOFs). Microporous Mesoporous Mater. 2020, 292. DOI: 10.1016/j.micromeso.2019.109724.

31. He, Y.; Zhang, Z.; Xiang, S.; Wu, H.; Fronczek, F. R.; Zhou, W.; Krishna, R.; O'Keeffe, M.; Chen, B., High separation capacity and selectivity of $\mathrm{C} 2$ hydrocarbons over methane within a microporous metal-organic framework at room temperature. Chemistry 2012, 18 (7), 1901-1904. DOI: 10.1002/chem.201103927.

32. Wu, H. X.; Chen, Y. W.; Lv, D. F.; Shi, R. F.; Chen, Y.; Li, Z.; Xia, Q. B., An indium-based ethanetrapping MOF for efficient selective separation of $\mathrm{C} 2 \mathrm{H} 6 / \mathrm{C} 2 \mathrm{H} 4$ mixture. Sep. Purif. Technol. 2019, 212, 51-56. DOI: 10.1016/j.seppur.2018.11.005.

33. Yuan, Y. N.; Wu, H. X.; Xu, Y. Z.; Lv, D. F.; Tu, S.; Wu, Y.; Li, Z.; Xia, Q. B., Selective extraction of methane from $\mathrm{C} 1 / \mathrm{C} 2 / \mathrm{C} 3$ on moisture-resistant MIL-142A with interpenetrated networks. Chem. Eng. J. 2020, 395. DOI: $10.1016 /$ j.cej.2020.125057.

34. Ma, H.; Ren, H.; Meng, S.; Sun, F.; Zhu, G., Novel porphyrinic porous organic frameworks for high performance separation of small hydrocarbons. Sci. Rep. 2013, 3, 2611. DOI: 10.1038/srep02611.

35. Zhang, Y. F.; Xiao, H. Y.; Zhou, X.; Wang, X.; Li, Z., Selective Adsorption Performances of UiO67 for Separation of Light Hydrocarbons C1, C2, and C3. Ind. Eng. Chem. Res. 2017, 56 (30), 86898696. DOI: $10.1021 /$ acs.iecr.7b01420.

36. He, Y.; Zhang, Z.; Xiang, S.; Fronczek, F. R.; Krishna, R.; Chen, B., A microporous metal-organic framework for highly selective separation of acetylene, ethylene, and ethane from methane at room temperature. Chemistry 2012, 18 (2), 613-619. DOI: 10.1002/chem.201102734.

37. He, Y.; Zhang, Z.; Xiang, S.; Fronczek, F. R.; Krishna, R.; Chen, B., A robust doubly interpenetrated metal-organic framework constructed from a novel aromatic tricarboxylate for highly selective separation of small hydrocarbons. Chem. Commun. (Camb.) 2012, 48 (52), 6493-6495. DOI: $10.1039 / \mathrm{c} 2 \mathrm{cc} 31792 \mathrm{c}$.

38. Yuan, B. Q.; Wang, X.; Zhou, X.; Xiao, J.; Li, Z., Novel room-temperature synthesis of MIL-100(Fe) and its excellent adsorption performances for separation of light hydrocarbons. Chem. Eng. J. 2019, 355, 679-686. DOI: 10.1016/j.cej.2018.08.201. 
39. Tang, Y. N.; Wang, S.; Zhou, X.; Wu, Y.; Xian, S. K.; Li, Z., Room temperature synthesis of $\mathrm{Cu}(\mathrm{Qc})(2)$ and its application for ethane capture from light hydrocarbons. Chem. Eng. Sci. 2020, 213. DOI: $10.1016 /$ j.ces.2019.115355.

40. Meng, S.; Ma, H. P.; Jiang, L. C.; Ren, H.; Zhu, G. S., A facile approach to prepare porphyrinic porous aromatic frameworks for small hydrocarbon separation. J. Mater. Chem. A 2014, 2 (35), 14536-14541. DOI: 10.1039/c4ta00984c.

41. Liao, P. Q.; Zhang, W. X.; Zhang, J. P.; Chen, X. M., Efficient purification of ethene by an ethanetrapping metal-organic framework. Nat. Commun. 2015, 6, 8697. DOI: 10.1038/ncomms9697. 